\title{
Temperature and humidity monitoring to identify ideal periods for liquefaction on Earth and Mars - data from the High Andes
}

\author{
Akos KERESZTURI ${ }^{1,2, *}$, Bernadett PAL ${ }^{1}$ and Akos GYENIS ${ }^{3,4}$ \\ 1 Konkoly Thege Astronomical Institute, MTA Centre for Excellence, Research Centre for Astronomy and Earth Sciences, \\ $\mathrm{H}-1121$ Konkoly Thege 15-17, Budapest, Hungary \\ 2 European Astrobiology Institute, virtual institute hosted by the European Science Foundation \\ 3 Korall-Print Bt., H-7625, Dr. Majorossy 43. Pecs, Hungary \\ 4 Budapest Institute of Technology and Economics, H-1111 M egyetem rkp. 3, Budapest, Hungary
}

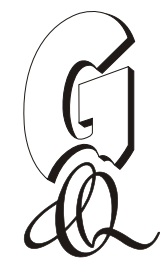

Kereszturi, A., Pal, B., Gyenis, A., 2020. Temperature and humidity monitoring to identify ideal periods for liquefaction on Earth and Mars - data from the High Andes. Geological Quarterly, 64 (4): 898-914, doi: 10.7306/gq.1559

\begin{abstract}
During an almost two week-long field campaign in the Atacama Desert high altitude region of Ojos del Salado volcano, temperature $(T)$ and relative humidity $(R H)$ values were monitored on the surface and $<1-5 \mathrm{~cm}$ sized rocks, focusing on the night-time values. The aim was to identify and evaluate potential temporal characteristics of daily $T$ and $R H$ changes, searching for ideal periods for deliquescence that has recently been proposed for Mars. Although the atmospheric pressure on Mars is much lower than on Earth, and the atmosphere is drier in general, the huge daily temperature fluctuation there could produce elevated humidity values at night-time; this aspect has thus been analysed on Earth at a desert location, where because of the high elevation night-time cooling is very strong, just like on Mars. Different nearby surface locations showed the same temporal $T / R H$ characteristics, but evident variations were observed between different days. Strong fluctuations could be observed on 10-20 minute long temporal scales, that might influence the deliquescence process, and should be accounted for in future missions aiming to analyse this process on Mars. Night-time periods were favourable for deliquescence. Among the modelled Mars-relevant salts $\left[\mathrm{CaCl}_{2}, \mathrm{Ca}\left(\mathrm{ClO}_{4}\right)_{2}, \mathrm{Mg}\left(\mathrm{ClO}_{4}\right)_{2}, \mathrm{NaCl}\right]$ the longest durations of possible deliquescence were for $\mathrm{CaCl}_{2}, \mathrm{Ca}\left(\mathrm{ClO}_{4}\right)_{2}$ and $\mathrm{Mg}\left(\mathrm{ClO}_{4}\right)_{2}, \sim 7-12$ hours for one day. The duration for deliquescence showed some increase along with the rising elevation, due to the decreasing night-time temperature. Thus despite the low humidity on Mars, the cold nights may cause elevated $R H$ towards deliquescence. The Atacama Desert locations analysed are a useful analogue of the deliquescence process on Mars. Fluctuation in $\mathrm{RH}$ was observed in night-time, suggesting that similar variability might be present on Mars, and that should be considered in the future, including in evaluating how fast the microscopic liquid formation progresses. Night-time slope winds expected on Mars might have a strong impact on the local $T / R H$ conditions. A more detailed analysis in the future should focus on identifying and separating regions with and without much of the expected night-time fluctuation.
\end{abstract}

Key words: deliquescence, humidity, high mountain, Mars, Mars analogue

\section{INTRODUCTION}

This work evaluates the on-site monitoring-based results of night-time $T$ and $R H$ measurements at the Ojos del Salado region of the High-Andes, near the Atacama Desert. The deliquescence process (by which a substance absorbs moisture from the air until it dissolves in the absorbed water and forms a solution), was found to be a realistic possibility producing microscopic liquid water on Mars today, despite the dry conditions. A thin-layer of liquid solution could form on the top layer of such hygroscopic salts that have the ability to absorb moisture from

\footnotetext{
* Corresponding author, e-mail: kereszturi.akos@csfk.mta.hu Received: November 10, 2019; accepted: July 8, 2020; first published online: October 8, 2020
}

the air. Onboard the ExoMars 2020 rover the HABIT instrument (Martin-Torres and Zorzano, 2018) will be able to detect this deliquescence process for the first time. While models of Martian atmospheric behaviour are often used to evaluate the possibility of deliquescence (Lewis, 2003), they usually consider "general or average" conditions, which in reality may be more variable. To better understand the atmospheric conditions' importance for deliquescence, this Earth-based Mars analogue site was surveyed to observe the temporal behaviour of temperature and humidity values (Farris and Davila, 2016), under partly Mars-relevant (reduced atmospheric pressure and humidity) conditions. The results gained there were complemented with Mars-relevant atmospheric modelling, as the joint evaluation of these two approaches can provide relevant information for the expected conditions on Mars. The contribution of this work to our current knowledge is to provide some example measurements of relative humidity and temperature changes in night-time at a high-altitude dry and cold Mars analogue site on the Earth, in order to inform research into Mars. 
Besides the occurrence of favourable conditions for deliquescence, the presence of specific Mars-relevant salts is also important; however, our study did not search for these, and this could be the target of a future longer mission. However, earlier information exist on the mineralogy of the Atacama region, mainly in situ though recently also from remote sensing data (Harris et al., 2016). These surveys demonstrated that several Mars-relevant hygroscopic salts are present there. The highest salt concentration occurs on salt flats, often dominated by chlorides, especially halite (Artieda et al., 2015), and gypsum (Amundson et al., 2012), which have been considered as useful Mars analogue materials (Osterloo et al., 2008) regarding their formation and potential biological relevance (Weng et al., 2018). Nitrates and perchlorates were also identified in variable abundance, which are most abundant in the driest Yungay region among the sites surveyed (McKay and Claire, 2016), partly because perchlorates are extremely soluble, and can remain only at the driest locations. Natural perchlorates $\left(\mathrm{ClO}_{4}^{-}\right)$have been identified at several dry areas on the Earth (including southwestern United States, southern Africa, United Arab Emirates, China, Antarctica, and Chile) with concentrations ranging from $10^{-1}$ to $10^{6} \mu \mathrm{g} / \mathrm{kg}$ (Jackson et al., 2015) - and this is abundant in the Atacama region. Oxychlorines have already been proposed as a reason for the lack or very low abundance of organic material in the soils of the Atacama Desert (Montgomery et al., 2019), thus they are important targets. At the three target sites analysed in this study, evaporites occur in variable amounts, although no specific compositional analysis has yet been realized there.

The Atacama Desert has been considered as a Mars analogue area on Earth because of its dryness (Stepinski and Stepinski, 2005), occurrence of oxidants (Catling et al., 2010; Smith et al., 2014; Jackson et al., 2015) and extreme habitats (Navarro-González et al., 2003; Heldmann et al., 2010; Wierzchos et al., 2013; Azua-Bustos et al., 2018). The characteristics of temperature and humidity daily cycles identified here, their repeatability, and the reasons for differences between various daily cycles, might have Mars-relevant consequences as regards formulating expectations for the deliquescence process there. In this work we mainly focus on night-time values measured in the High Andes; the daytime values are much more uncertain and are noted only for context. The data we have obtained may help to identify those temporal characteristics (like certain parts of daily cycles, required temporal resolution, scale of fluctuations etc.) that should be a focus of future observations and planning.

During the geological history of Mars there were periods when the planet likely had rivers, lakes (Cabrol and Grin, 1999; Fassett et al., 2008; Czechowski et al., 2013; Ehlmann et al., 2016) and even large standing liquid water bodies (Tokano et al., 2005). Liquid water cannot exist in large volumes there today, mainly because of the thin atmosphere, low temperature and general dryness. However, based on new results, it can emerge at a microscopic scale on the surface of hygroscopic minerals (Reiss et al., 2010; Nikolakakos and Whiteway, 2018), if the circumstances are favourable (Losiak et al., 2015; Pal and Kereszturi, 2017). The necessary conditions, elevated humidity and temperature can be met on Mars, as the meteorological observations of the Rover Environmental Monitoring Station (REMS) instrument onboard Curiosity rover showed a few years ago (Torres et al., 2015). Deliquescence is an important step toward the potential emergence of bulk liquid brines (Farris and Davila, 2017). There are numerous other studies indicating the existence of liquid water or brines on Mars (Zorzano et al., 2009), that might facilitate movement on the Martian surface in the form of streaks emanating from Dark
Dune Spots (Kereszturi and Rivera-Valentin, 2012, 2016), Recurring Slope Linae (McEwen et al., 2011; Ojha et al., 2015) while what look like droplets on the leg of the Phoenix lander have also been observed (Renno et al., 2009).

\section{BACKGROUND INFORMATION}

The study site: the Ojos del Salado (6893 m, 2706'34" S, $68^{\circ} 32$ '32" W) is the highest volcano on Earth (Óscar, 1995), with an elevation of $6893 \mathrm{~m}$ in the Atacama Desert - Altiplano region, above the Puna de Atacama plain. The region is a desert without vegetation or soil cover (Fig. 1). Due to the undulating topography and high altitude, permafrost is present (Cobos and Corte, 1990; Ahumada, 2002) with some glacier remnants (Oyarzun, 1987). The morphology of the surface is dominated by rocks and boulders; at a few locations ripples (rarely dunes) are also observable. Ojos del Salado has the highest altitude snowline (Clapperton, 1994), however >6500 m the terrain is mostly (but not always) snow covered (Amman et al., 2001) and it hosts the highest altitude lakes and desert region on Earth.

The climatic conditions are not well-known, partly because of the stochastic changes and the poor observational coverage. From the remote sensing analysis of Gspurning et al. (2006), it is difficult to determine the snow coverage, as fresh snow might sublimate within hours. There is a characteristic night-time temperature drop, occasionally $<-10^{\circ} \mathrm{C}$ even during summertime, and above $6000 \mathrm{~m}$ it is often $<-10^{\circ} \mathrm{C}$ even in daytime. The climatic snowline is situated $\sim 7000 \mathrm{~m}$, and a high-altitude desert can be found below 6000 m (Ammann et al., 2001; Azócar and Brenning, 2010; Nagy et al., 2014a, b; Nagy, 2019). Precipitation is occasionally present but only in the form of snow (no rain $>5000 \mathrm{~m}$ altitude), mainly during local winter. The snow might sublimate away, but a small amount of ephemeral runoff can occasionally be generated by the melting snow.

Temperature and humidity monitoring have already been realized in the Atacama region at lower altitude locations, and at other Mars analogue sites on the Earth. Azua-Bustos et al. (2015) surveyed the driest Yungay region of the Atacama Desert and the even drier María Elena South location, reporting a mean atmospheric relative humidity of $17.3 \%$, a constant $14 \%$ at the depth of $1 \mathrm{~m}$ in the soil, and found a number of viable bacterial species there. Based on the climate and moisture data of four years (1994-1998) reported by McKay et al. (2003) there was only one significant rain event of $2.3 \mathrm{~mm}$, near midnight local time. This may have been a rain out of a heavy fog that produced liquid water in the soil for $65-85$ h over the 4 years. However, all of these earlier measurements were realized at much lower altitudes (usually $<1100$ m elevation), thus it is important to extend the analysis to higher levels, as at a lower-pressure environment the atmospheric variability might be larger, and closer to that relevant for the Martian surface. Unfortunately no remote data recording was realistic at this altitude, because the strong winds often redistribute dust, and any unguarded detector may be covered with a thick sediment layer and produce false data. As a result only a relatively short interval of data recording was possible here, during a manned expedition.

For deliquescence to take place on Mars, elevated atmospheric humidity and hygroscopic salts need to be present on the otherwise generally dry planet. Humidity can be elevated during night-time because of the very low temperature, and so the relative humidity could increase substantially. Under the conditions measured by the REMS instrument at Gale Crater on Mars, some chlorine-containing salts can hydrate and others 

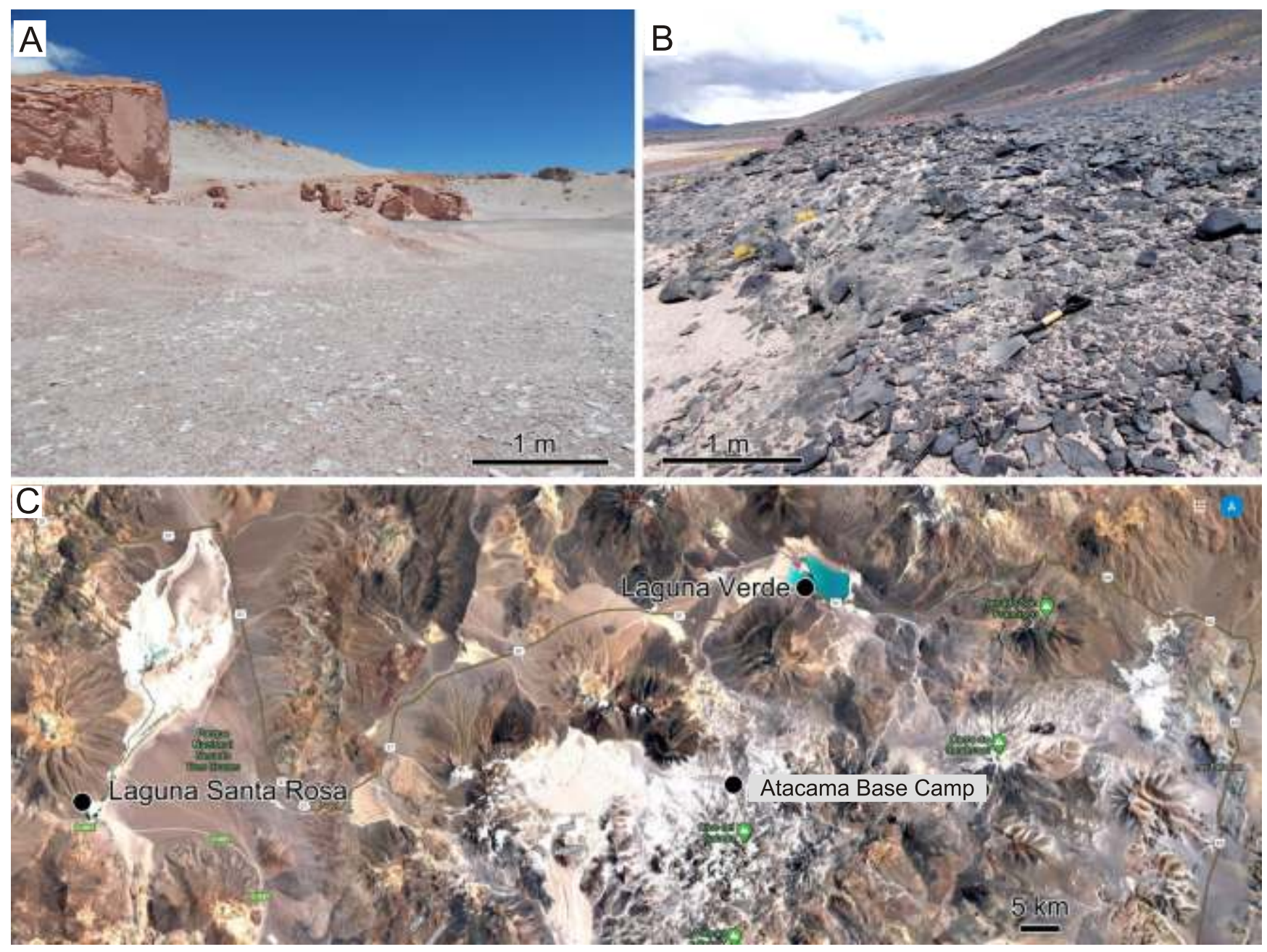

Fig. 1. Images of the area, showing the general outlook of the barren, rocky debris-covered surface (A, B) and a map of the locations of measurements (C)

dehydrate on daily cycles based on laboratory tests (Gough et al., 2019), however, atmospherically based hydration of salts may be very slow. Aqueous solutions from the interaction of various perchlorates are expected to emerge around the Phoenix landing site but not probable at the Curiosity landing site of Gale crater (Primm et al., 2018); however, deliquescence is expected there (Rivera Valentín et al., 2018). Analysing the Phoenix landing site, $R H$ was usually $<5 \%$ in the day and $>95 \%$ at night-time, the transition between the two values being rapid (Zent et al., 2016). According to recent results (Martin-Torres et al., 2015; Pal and Kereszturi, 2017) deliquescence is a realistic possibility for microscopic liquid water emergence on Mars under current conditions. Although in the High-Andes region there are various hygroscopic salts, which might provide ideal surfaces for the deliquescence process, in this work only the meteorological conditions, and Mars-related theoretical occurrence of deliquescence, were analysed.

Perchlorates and chlorates were first identified by the Wet Chemistry Laboratory experiment on the Phoenix Lander on Mars (Hecht et al., 2009; Kounaves et al., 2010; Toner et al., 2014a). The existence of perchlorates was further indicated by the Thermal and Evolved Gas Analyzer (Boynton et al., 2009), of the Sample Analysis at Mars instrument onboard the Curiosity rover (Glavin et al., 2013) and perchlorates were also detected spectroscopically by the Mars Reconnaissance Orbiter
(Ojha et al., 2015). Perchlorates and chlorates are popular among researchers due to their ability to considerably lower the freezing point of water, and to their hygroscopic nature. These properties suggest the potential for liquid water on Mars in spite of the cold and dry, frigid conditions (Gough et al., 2011; Nuding et al., 2014; Toner et al., 2014a, 2015a, b). Because of the great variability of meteorological conditions on Mars, several aspects of the Martian $\mathrm{H}_{2} \mathrm{O}$ cycle are awaiting discovery (Martinez et al., 2017).

\section{METHODS}

In this study, in situ temperature and humidity measurements were analysed and compared to Martian atmospheric modelling-based trends. At the field sites atmospheric and shallow subsurface temperature and relative humidity were measured using 8 sensors per site. These were used at three different altitudes during the field trip on the slopes of Ojos del Salado volcano in the High Andes and Atacama region for a total period of 12 days, at 3810, 4328 and $5260 \mathrm{~m}$ a.s.l. (Kereszturi, 2019).

SHT21 Humidity and Temperature Sensor IC instruments $(4 \times 1.5 \times 0.5 \mathrm{~cm})$ produced by Sensirion company, were used. 
These were equipped with capacitive type humidity sensors, band gap temperature sensors and a specialized digital integrated circuit - all on a single CMOS chip. The sensors provide calibrated, linearized signals in digital I2C format. The resolution of SHT2x can be changed by command (8/12bit up to $12 / 14 \mathrm{bit}$ for $R H / T$ ). The $R H$ resolution of the instrument is better than $0.7 \%$, but can reach up to $6 \%$ below zero Celsius; the temperature resolution is better than $0.04^{\circ} \mathrm{C}$ (operating range -40 to $125^{\circ} \mathrm{C}$ ).

The detectors acquired measurements every 5 minutes. They were exposed on the surface to be able to react quickly to changes in the environment, and arranged in a $1 \mathrm{~m}^{2}$ area $<1 \mathrm{~m}$ distance apart at each site (Fig. 2). Four types of placing were used in order to see possible differences related to $\mathrm{cm}$-scale topographic undulations (shadowing). The first placing type was a nearly smooth area directly on the surface, the second at the bottom of a 12-14 cm diameter, 8-12 cm deep pit (depression), the third next to a stone (min. $8 \mathrm{~cm}$ high) at its east and west sides, the fourth at the bottom of a 8-12 cm deep pit as noted above, but covered with a stone from above (that allows air to flow through the depression; Fig. 2).
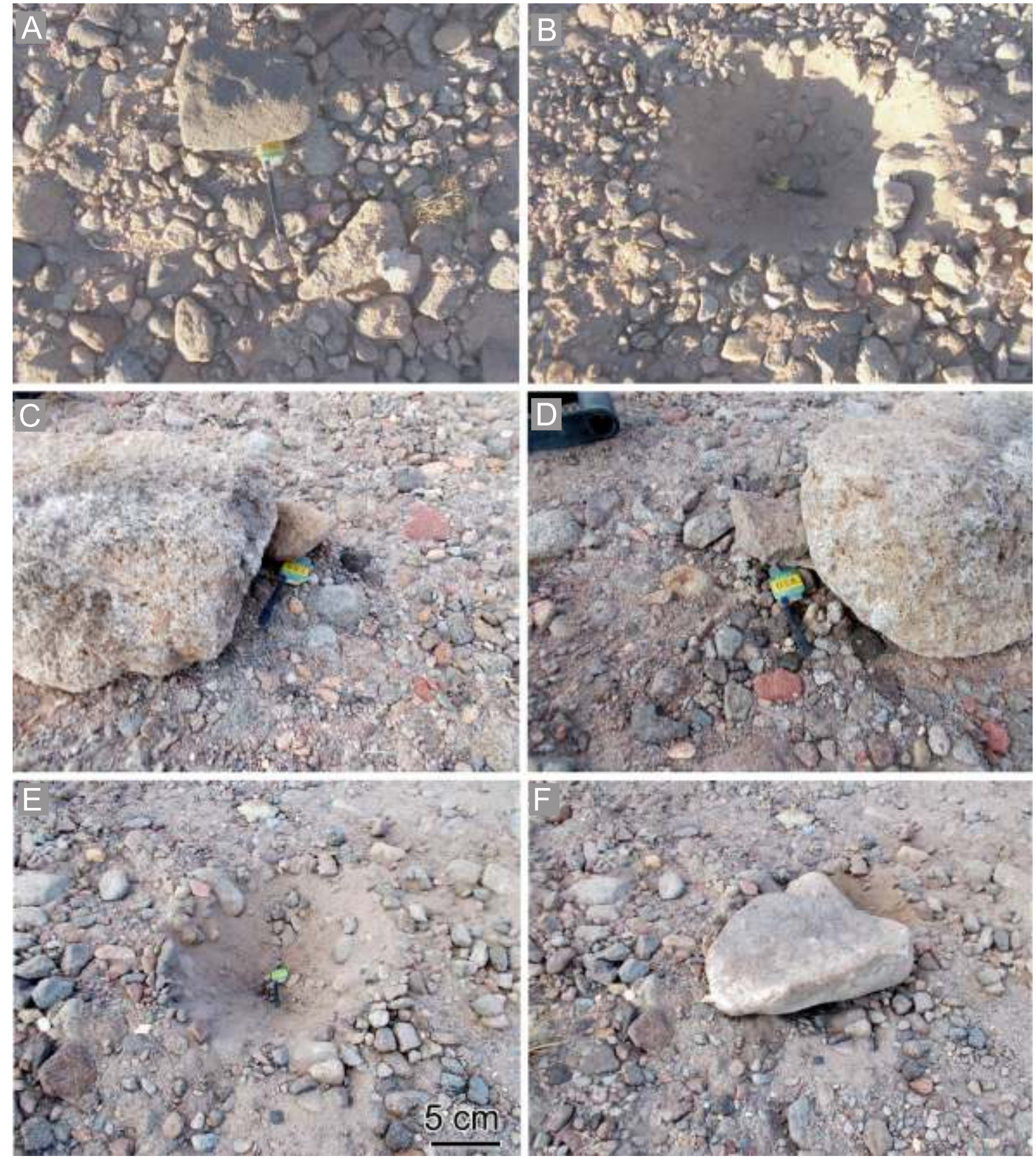

Fig. 2. The placing of detectors (yellow-green box with black rod)

A - exposed on a barren surface; $\mathbf{B}$ - inside a small pit; C, D - beside rocks; E, $\mathbf{F}$ - inside a pit covered by a rock; the $5 \mathrm{~cm}$ scale at the bottom is approximately valid for all insets 
Although the measurements targeted the night-time periods, some observations from the daytime dataset are interesting too. In order to provide further compare with Mars-relevant aspects, we analysed the measurements in contrast with Martian Recurring Slope Lineae sites, Horowitz Crater and Newton Basin (McEwen et al., 2011). We obtained surface temperature and relative humidity curves from model calculations by Laboratoire de Météorologie Dynamique Mars General Circulation Model (LMDZ GCM), detailed in Forget et al. (1999), including a water cycle as described in Navarro et al. (2014).

To calculate the relative humidity on Mars, we need the water vapour volume mixing ratio at the surface. Since a GCM does not model this at the Martian surface, but at $\sim 4 \mathrm{~m}$ above it, we assume that the area between the surface and this height layer is well-mixed (this assumption is roughly acceptable as the best available approach, because of near-surface mixing-induced wind shear even in a relatively stable atmosphere). With this approximation, we consider that the water vapour volume mixing ratio at the surface is equal to the value at $\sim 4 \mathrm{~m}$. The relative humidity is then derived as:

$$
R H=\frac{Q_{0}}{Q_{\text {sat }}}
$$

where: $Q_{0}$ is the estimated water vapour volume mixing ratio at the surface.

According to Martin-Torres et al. (2015) and Pal and Kereszturi (2017) deliquescence is a realistic possibility for microscopic liquid water emergence on Mars under current conditions. Although in the High Andes region there are various hygroscopic salts which might provide the ideal surfaces for the deliquescence process, in this study only the meteorological conditions and Mars-related theoretical occurrence of deliquescence were analysed.

We examined the expected potential behaviour of 5 salts altogether, evaluating the model based results and the measured parameters in order to see whether these components liquefy on Mars and the analysed Earth analogue locations: calcium perchlorate: $\mathrm{Ca}\left(\mathrm{ClO}_{4}\right)_{2}$ (Toner et al., 2014b), magnesium perchlorate: $\mathrm{Mg}\left(\mathrm{ClO}_{4}\right)_{2}$ (Möhlmann and Thomsen, 2011), calcium chloride: $\mathrm{CaCl}_{2}$ (Davila et al., 2010), sodium chloride: $\mathrm{NaCl}$ and magnesium sulphate: $\mathrm{MgSO}_{4}$ (Chevrier et al., 2012). Magnesium perchlorate was identified by the Phoenix lander (Hecht et al., 2009) and calcium perchlorate was also identified at the Martian surface; these are the most probable salts to liquefy through deliquescence under current conditions, mostly because of their low eutectic temperature.

\section{RESULTS}

The numerical summary of the observed temperature and humidity values can be seen in Table 1, while some observed typical daily curves at the Ojos del Salado volcano are shown in Figure 3. The temperature and relative humidity curves exhibit general trends that are related mostly to the daily cycles, with increased temperature in the day and increased humidity at night-time, although they showed some specific features too. These observations suggest that the parameters recorded are more site- (and local conditions-) dependent than related to any possible specific characteristics of certain detectors. The temperature and humidity curves are anticorrelated to each other, according to expectations.

An overview of values of the temperature and humidity measured are indicated in Table 1 where all detectors were used to calculate the average, minimum and maximum values for night-time temperatures, using all sensors from 2 days at Laguna Santa Rosa, 2 days at Laguna Verde, and 4 days at Atacama Base Camp. For daytime values our own measurements were combined with other studies (Gspurning et al., 2006; Azócar and Brenning, 2010) to evaluate the range and minimum and maximum values. Evaluating the numbers in Table 1, subzero temperatures might appear at all locations even

Summary of measurements

\begin{tabular}{|c|c|c|c|c|}
\hline \multirow{2}{*}{ Location } & $\begin{array}{c}\text { Laguna Santa } \\
\text { Rosa }\end{array}$ & Laguna Verde & \multicolumn{2}{|c|}{ Atacama Base Camp } \\
\hline \multirow{3}{*}{ Daytime $T\left[C^{\circ}\right]$} & $\min$ & 1.4 & -2.7 & -12.2 \\
\cline { 2 - 5 } & $\max$ & 22 & 23 & 18 \\
\cline { 2 - 5 } & average & 14.4 & 8.6 & 8.0 \\
\hline \multirow{3}{*}{ Daytime $R H[\%]$} & $\min$ & 3.0 & 6.7 & 0.7 \\
\cline { 2 - 5 } & $\max$ & 78.5 & 98.4 & 89.7 \\
\cline { 2 - 5 } & average & 11.4 & 20.8 & 12.4 \\
\hline \multirow{3}{*}{ Nighttime $T\left[\mathrm{C}^{\circ}\right]$} & min & -0.7 & -3.9 & -13.5 \\
\cline { 2 - 5 } & max & 17.3 & 17.5 & 7.8 \\
\cline { 2 - 5 } & average & 3.4 & 2.9 & -2.3 \\
\hline \multirow{3}{*}{ Nighttime $R H[\%]$} & min & 30.7 & 26.2 & 32.2 \\
\cline { 2 - 5 } & max & 85.3 & 100.0 & 94.7 \\
\cline { 2 - 5 } & average & 29.6 & 39.1 & 33.0 \\
\hline
\end{tabular}

Daytime temperatures are not part of the analysis 

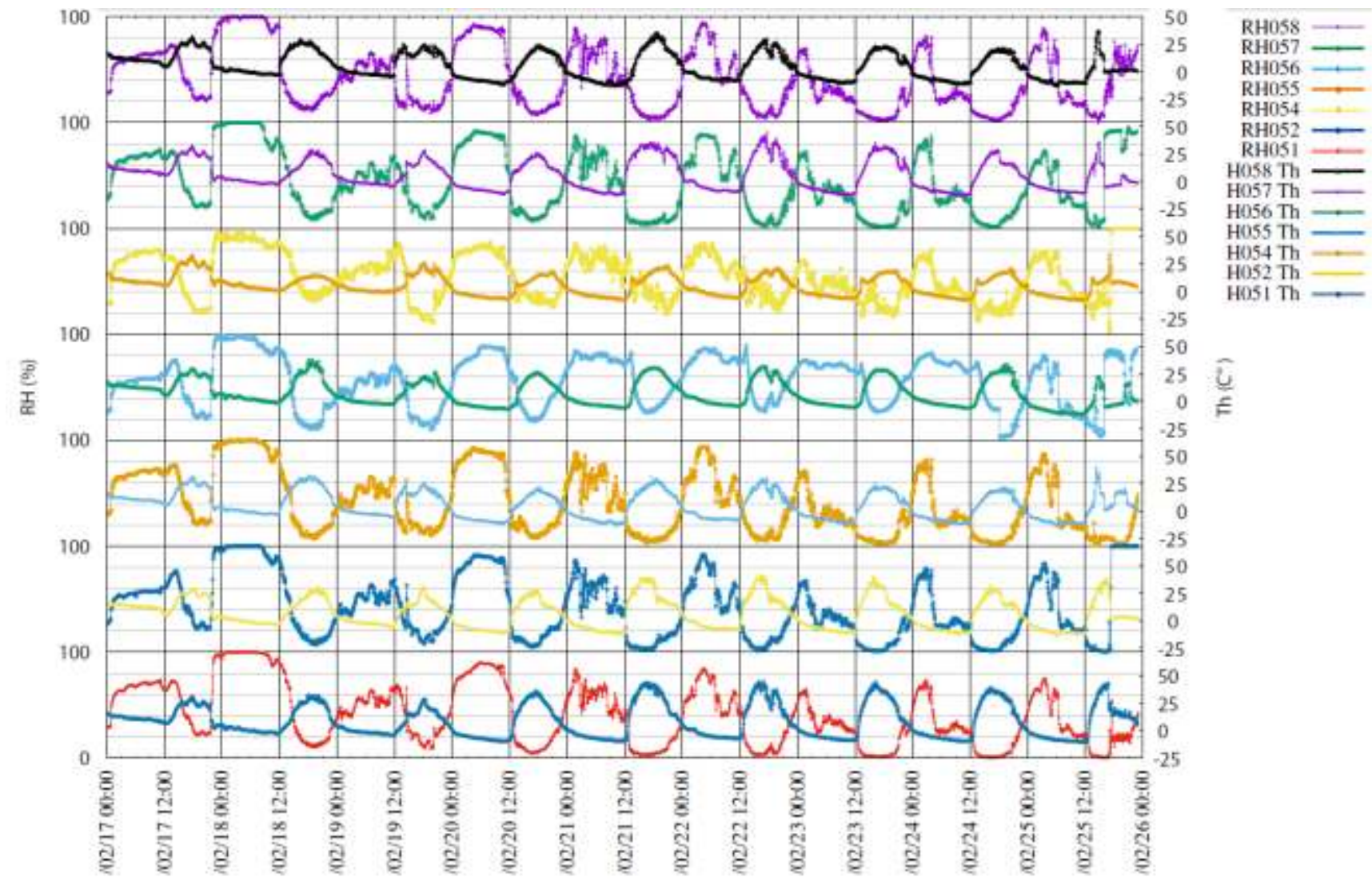

Fig. 3. Summary of all curves recorded where different colours mark different detectors (top right corner)

Please note that the last two days of the observations have not been considered during the analysis as in these cases the detectors were situated close to the location of site where melting was taking place and were covered by wet sediments; thus, they were not realistic. Placing of the detectors at each site was done according to: 51 - exposed on a barren surface, 52 and 54 -inside a small pit, 55 and 56 - beside rocks, 57 and 58 - inside a pit covered by a rock

in daytime too, however, even at night-time it was not necessary to go below zero. The daytime and night-time average values both decreased with increased altitude. A high range of daily fluctuation can be observed for both temperature and humidity. The relative humidity in particular could show extreme values; in the daytime it was usually very low, $11-21 \%$ but rarely (during snowfall) could reach saturation. At night-time, it never decreased below $\sim 26-30 \%$, but could also reach saturation. According to expectations, the average night-time $\mathrm{RH}$ was higher than the average daytime $\mathrm{RH}$.

In Table 1 we can see the overall daytime and night-time temperature and relative humidity values by measuring location. As the altitude increases the temperature drops, which shows here in the daytime and night-time minimum temperatures with an $\sim 10^{\circ} \mathrm{C}$ decrease between the lowest and the highest measuring locations. The same is apparent if we look at the daytime and night-time average temperatures. As the pressure decreases with increasing elevation, the amount of water that the atmosphere can hold also decreases. However, with lower amounts of water vapour in the air, relative humidity levels could be high because of the decreasing temperature. This might be the reason for the table showing no clear trend in the relative humidity minimum, maximum or average levels - in colder nights, a smaller absolute humidity can produce elevated relative humidity.

A general overview of the recorded data and characteristics of daily curves are shown in Figure 3 . The curves recorded by different detectors show similar trends on the same days (comparing the curve sections below and above each other). This shows that the location types of the different detectors cause much smaller differences than the differences between various days. However differences between particular days could be easily identified. Variability on an hourly scale (the finest observable fluctuation of the curves) is also present, especially in the night-time humidity values, for almost all nights.

There were strong fluctuations in certain parts of the dataset. We compared these fluctuations between nearby detectors with each other, to see if they all recorded the same variability (see some examples for the Laguna Santa Rosa site in the Figure 4A), while in the case of relative humidity measurements, the trends between different detectors were similar. The numbers by the curves show the identification number of each detector there. The fluctuations show the same trends at different detectors roughly $1 \mathrm{~m}$ apart, both on exposed surfaces or in shadowed and covered locations. Similar trends are visible at all detector location types: a small pit $(51,54)$, next to a stone $(58,57)$, under a stone $(55)$. Since similar trends are observable at all detector location types, these small placement differences (inside a pit, next to or under a stone etc.) do not influence the trends substantially.

Whole-night example curves are visible in Figure 4B. The night-time temperature (lower) and relative humidity (upper) curve pairs of day 2 (thicker) and day 1 (thinner) of detector no. 52 are provided. They show examples for a cloudy, less cold 

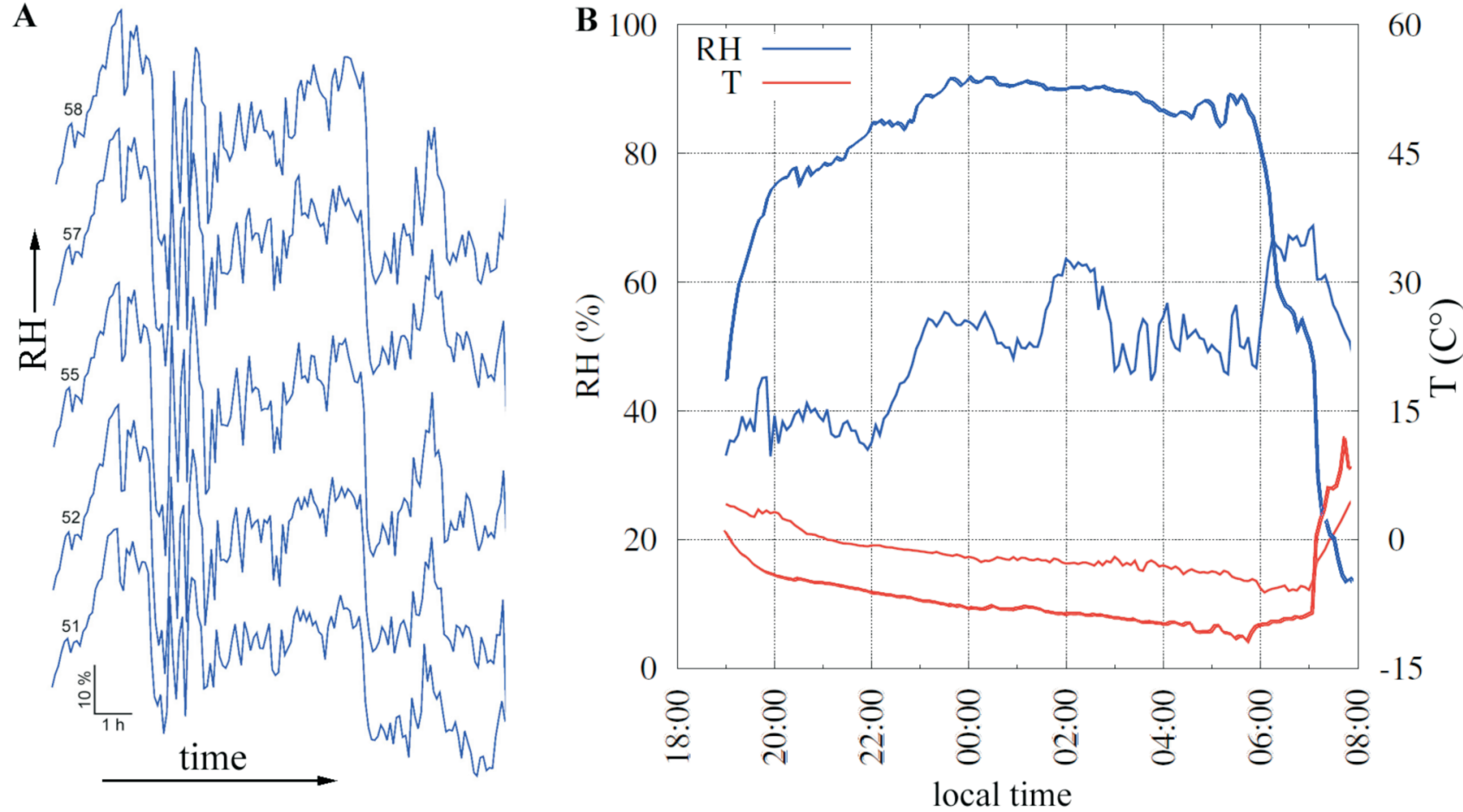

Fig. 4. Example of night-time relative humidity curves

A - 3rd day at the Atacama Base Camp of the different detectors, to demonstrate that the change in relative humidity recorded by 5 different detectors, located close to each other, show the same $R H$ values (vertical axis) as time elapsed (horizontal axis); $\mathbf{B}$ - night-time temperature (lower) and relative humidity (upper) curve pairs of day 2 (thicker) and day 1 (thinner) curves of detector no. 52

and windy (day 1 ) and a cloudless thus colder (day 2) night-time with much smaller fluctuations in the second case.

Night-time temperature variations could also be observed. These were usually not larger than $1-2^{\circ} \mathrm{C}$ during an hour in night-time, but occasionally could reach up to $2^{\circ} \mathrm{C}$ rise/fall in 10 minutes. The temporal density and amplitude of fluctuations increased along with the topographic elevation. The level of fluctuation also showed differences between various days, for example in the Atacama Base Camp on day 2 the daytime fluctuations were $\sim 2-4^{\circ} \mathrm{C}$ while on day 1 during $>10$ occasions they reached $>5^{\circ} \mathrm{C}$.

Some specific events are worth highlighting. Relatively brief changes in temperature and related increase in relative humidity could be observed at several sites and during several periods. The reason probably relates to the strong winds that can carry somewhat warmer or colder air masses to the location of the detector. A snowstorm at Laguna Verde on day 2 produced saturated conditions during the night for 6-7 hours. At the Atacama Base Camp the daily fluctuations were much stronger on day 1 than on day 2 , together with more elevated $R H$ on day 2 (average $40.6 \%$ ) than day $1(25.7 \%)$.

\section{POSSIBILITY FOR DELIQUESCENCE}

Figure 5 below shows the presumed time intervals (as vertical blue bars), when the circumstances are favourable for deliquescence of certain salts. The calculated relative humidity values are shown on the left $y$ axis, and the surface temperatures on the right $y$ axis. The eutectic temperatures and relative humidity levels needed for deliquescence are indicated with hori- zontal lines denoting the salt in question. The ideal time periods are indicated by light blue rectangles showing the beginning and end of the ideal window.

In Figure 5, we can see that the relative humidity stayed almost constant throughout the night on the second day, resulting in long and continuous possible periods suitable for deliquescence. On the third day the relative humidity fluctuated quite heavily during the night, and this resulted in shorter, more scattered ideal periods; the overall ideal time window did not change between the two days. Table 2 gives a summary for two example days at the Atacama Base Camp, which was the highest altitude among the locations analysed, probably the most Mars-relevant one among the sites surveyed.

In Table 2 one can see the two example days showing different deliquescence characteristics. On day 2 at the Atacama Base Camp all the salts except $\mathrm{Mg}(\mathrm{SO})_{4}$ could liquefy, and the ideal time periods are long and continuous. On day 3 the relative humidity levels were fluctuating throughout the night and dropped below $60 \%$ after $\sim 2$ am, which led to shorter and more scattered ideal periods.

In Figure 6 one can see the total length of ideal time intervals for deliquescence. The measurements were taken at Laguna Santa Rosa for 1 day, Laguna Verde for 2 days and at the Atacama Base Camp for 4 days. There were 7 differently placed detectors at each site and their measured ideal time windows were summed for each day. Therefore there are more measurement points at the Atacama Base Camp than at Laguna Santa Rosa for example, because the same detector has 4 points at the former site, one for every day with ideal time periods. An example of our calculations is as follows: at the third day at Atacama Base Camp, the detector counted 51 (exposed 
A Daily cycle of surface temperature and relative humidity

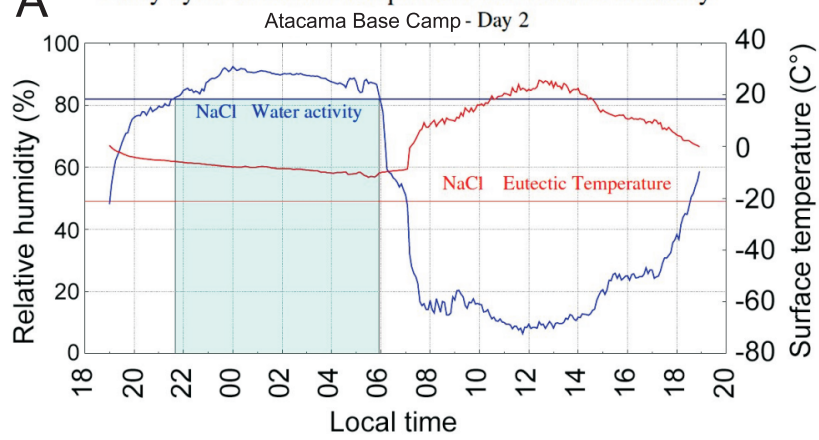

C Daily cycle of surface temperature and relative humidity

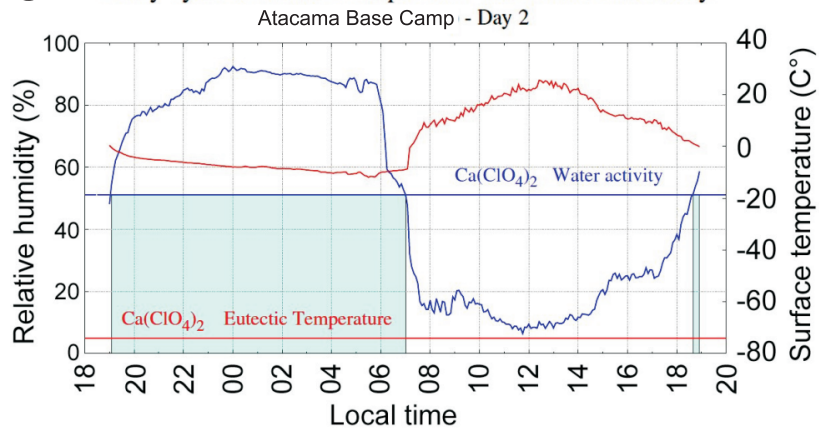

E Daily cycle of surface temperature and relative humidity

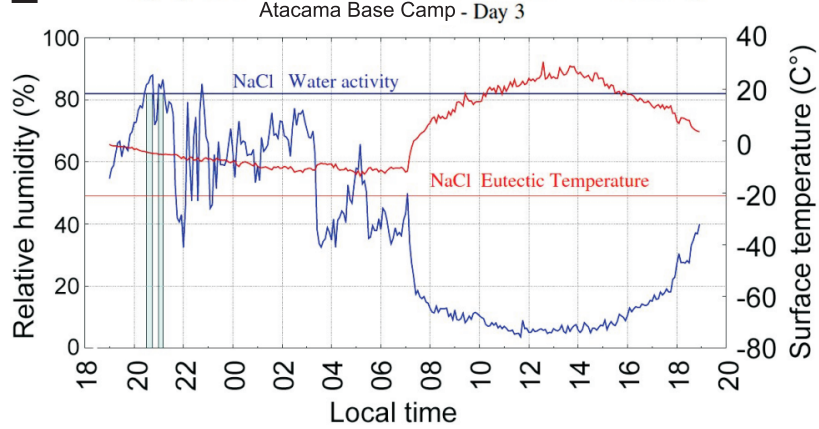

$G$ Daily cycle of surface temperature and relative humidity

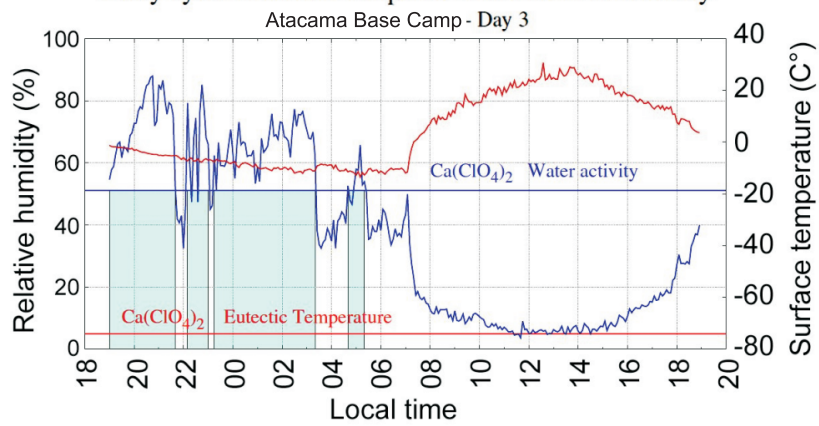

B Daily cycle of surface temperature and relative humidity

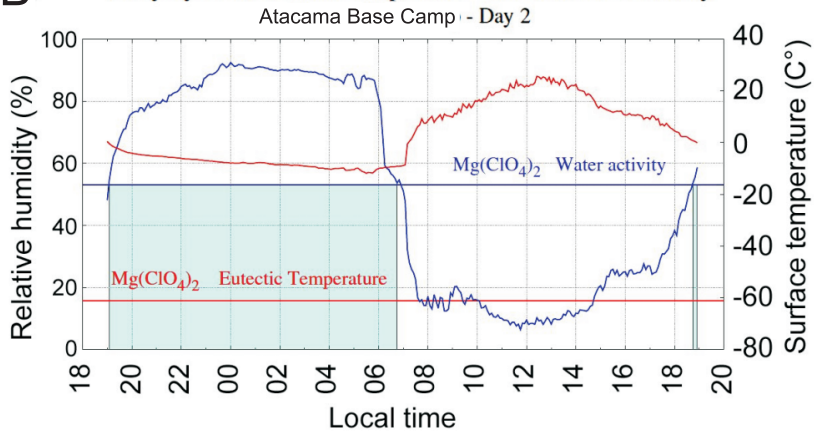

D Daily cycle of surface temperature and relative humidity

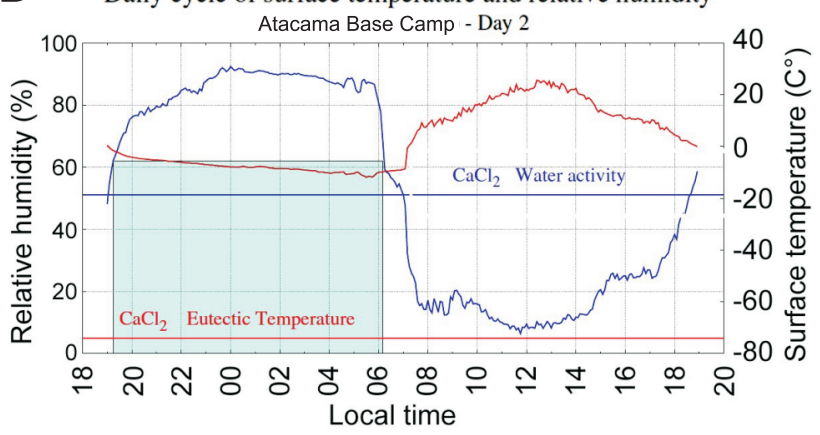

F Daily cycle of surface temperature and relative humidity

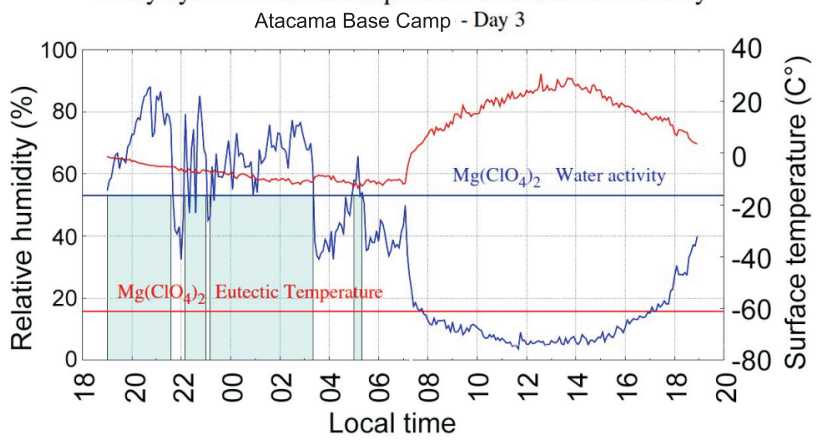

H Daily cycle of surface temperature and relative humidity

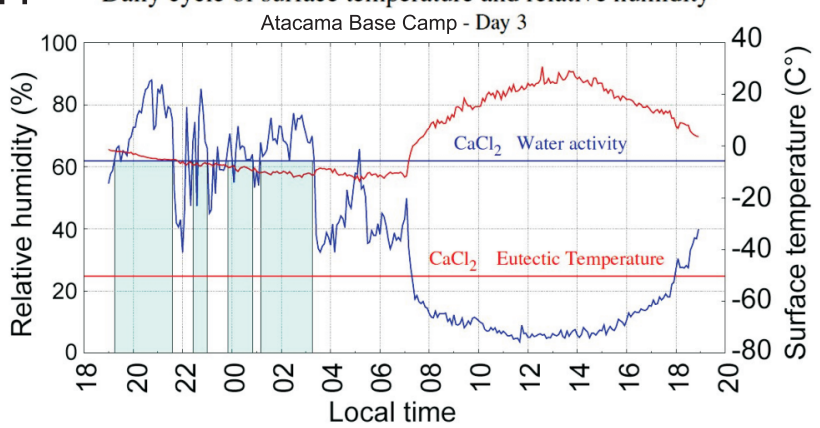

Fig. 5. Daily temperature and relative humidity curves of four Mars-relevant salts

The calculated relative humidity values are shown on the left $y$ axis, and the surface temperatures on the right $y$ axis. In the A, B, C and D insets the second day of measurement is shown at the Atacama Base Camp with 4 different salts denoted. In insets $\mathrm{E}$, $\mathrm{F}$, $\mathrm{G}$ and $\mathrm{H}$ the next day is shown at the same location with the same salts. There is a notable difference between the relative humidity behaviour of the two days. On the third day (right column) it fluctuated during the night, causing the ideal time periods to be divided into shorter durations 
Summary of example salts' deliquescence periods on days at the Atacama Base Camp

\begin{tabular}{|c|c|c|c|c|c|c|}
\hline \multirow{2}{*}{ Location } & \multirow{2}{*}{ Salt type } & \multicolumn{2}{|c|}{ Beginning of ideal period } & \multicolumn{2}{|c|}{ End of ideal period } & \multirow{2}{*}{$\begin{array}{l}\text { Total duration } \\
{[\mathrm{h}]}\end{array}$} \\
\hline & & Date & Local time & Date & Local time & \\
\hline \multirow{5}{*}{$\begin{array}{c}\text { Atacama Base Camp } \\
\text { 2. day }\end{array}$} & $\mathrm{CaCl}_{2}$ & $2018 / 2 / 19$ & 19:15 & $2018 / 2 / 20$ & $06: 10$ & 10.9 \\
\hline & $\mathrm{Ca}\left(\mathrm{ClO}_{4}\right)_{2}$ & $2018 / 2 / 19$ & 19:05 & $2018 / 2 / 20$ & $18: 55$ & 12.2 \\
\hline & $\mathrm{Mg}\left(\mathrm{ClO}_{4}\right)_{2}$ & 2018/2/19 & 19:05 & $2018 / 2 / 20$ & $18: 55$ & 11.9 \\
\hline & $\mathrm{Mg}(\mathrm{SO})_{4}$ & - & 00:00 & - & $00: 00$ & 0.0 \\
\hline & $\mathrm{NaCl}$ & $2018 / 2 / 19$ & $21: 40$ & $2018 / 2 / 20$ & $05: 55$ & 8.3 \\
\hline \multirow{16}{*}{$\begin{array}{c}\text { Atacama Base Camp } \\
\text { 3. day }\end{array}$} & \multirow{7}{*}{$\mathrm{CaCl}_{2}$} & \multirow{4}{*}{$2018 / 2 / 20$} & 19:15 & \multirow{3}{*}{$2018 / 2 / 20$} & 19:25 & \multirow{7}{*}{7.2} \\
\hline & & & 19:35 & & $21: 35$ & \\
\hline & & & $22: 40$ & & 23:00 & \\
\hline & & & $23: 50$ & \multirow{4}{*}{$2018 / 2 / 21$} & 00:00 & \\
\hline & & \multirow{3}{*}{$2018 / 2 / 21$} & $00: 10$ & & $00: 50$ & \\
\hline & & & $01: 10$ & & $02: 15$ & \\
\hline & & & $02: 25$ & & $05: 10$ & \\
\hline & \multirow{4}{*}{$\mathrm{Ca}\left(\mathrm{ClO}_{4}\right)_{2}$} & \multirow{3}{*}{$2018 / 2 / 20$} & 19:00 & \multirow{2}{*}{$2018 / 2 / 20$} & $21: 40$ & \multirow{4}{*}{7.4} \\
\hline & & & $22: 40$ & & $23: 00$ & \\
\hline & & & $23: 15$ & \multirow{2}{*}{$2018 / 2 / 21$} & 03:20 & \\
\hline & & $2018 / 2 / 21$ & 05:00 & & $05: 20$ & \\
\hline & \multirow{3}{*}{$\mathrm{Mg}\left(\mathrm{ClO}_{4}\right)_{2}$} & \multirow{3}{*}{$2018 / 2 / 20$} & 19:00 & \multirow{2}{*}{$2018 / 2 / 20$} & $21: 35$ & \multirow{3}{*}{8.6} \\
\hline & & & $22: 40$ & & 23:00 & \\
\hline & & & $23: 25$ & $2018 / 2 / 21$ & $05: 10$ & \\
\hline & $\mathrm{Mg}(\mathrm{SO})_{4}$ & - & 00:00 & - & $00: 00$ & 0.0 \\
\hline & $\mathrm{NaCl}$ & $2018 / 2 / 20$ & $20: 30$ & $2018 / 2 / 20$ & $21: 10$ & 0.6 \\
\hline
\end{tabular}

on the barren surface) measured ideal conditions for $\mathrm{Ca}\left(\mathrm{ClO}_{4}\right)_{2}$ between 19:00-21:40, 22:30-03:20 and 05:00-05:10 (the minimum ideal window was 10 minutes, shorter periods were excluded). This summed up is 7 hours and 30 minutes, 7.5 hours, which is then shown as a single point in Figure 6. Calcium perchlorate $\left[\mathrm{Ca}\left(\mathrm{ClO}_{4}\right)_{2}\right]$ and magnesium perchlorate $\left[\mathrm{Mg}\left(\mathrm{ClO}_{4}\right)_{2}\right]$ showed the longest total ideal time period, with calcium chloride $\left(\mathrm{CaCl}_{2}\right)$ behind them with a few hours in total. The same "order of salts" could be identified at each of the three sites, suggesting that material-related properties of the salts could strongly influence the result at each site. Magnesium sulphate $\left[\mathrm{MgSO}_{4}\left(\mathrm{H}_{2} \mathrm{O}\right)\right]$ could only liquefy through deliquescence at Laguna Verde, while sodium chloride $(\mathrm{NaCl})$ could liquefy at all the locations measured; however, the total times were usually shorter than those for the perchlorates.

Taking Table 1 into consideration, we can see that Laguna Santa Rosa shows shorter ideal time periods, most likely due to the lower average relative humidity. Out of the three locations, Laguna Santa Rosa has the highest temperatures, both average and minimum. However, the average relative humidity is the lowest here. Laguna Verde has the highest relative humidity values according to the data, but given the snowfall here, the relative humidity average is biased by the saturated detectors. As we would assume, the average temperatures are the lowest at the highest altitude, at the Atacama Base Camp. We see no significant variation between Laguna Verde and the Base Camp. This is most likely due to the balance between their respective temperature and relative humidity levels; this also suggests that the true average relative humidity of Laguna Verde should be somewhere between the averages of Laguna Santa Rosa and the base camp.

In Figure 7 one can see how the ideal time periods for deliquescence were arranged by local time, location and salt type. The beginnings and the ends of ideal periods are denoted by differently shaped and coloured symbols according to the specific salts. At Laguna Santa Rosa we can see that almost every ideal window is at least 5 hours long, starting either $\sim 10 \mathrm{pm}$, or $\sim 2 \mathrm{am}$. There were only 4 instances when the ideal window was shorter. At Laguna Verde there is a significant group starting $~ 7 \mathrm{pm}$ and ending between 3 and 10 am gradually, depending on the salt. Another group is from 8-9 pm to 10-11 am. There are few instances during the night, as well as a few short time windows in the early morning hours. The third group is located at the top right, starting in the late afternoon hours and ending before midnight. Atacama Base Camp (the highest elevation site) shows the most ideal windows, but this is also because there are 4 days of data, while there are only 2 days from Laguna Verde, and 1 day from Laguna Santa Rosa. On the graph there is an almost continuous $45^{\circ}$ line consisting of very short time windows, possibly due to temperature or relative humidity fluctuations close to the minimum ET (eutectic temperature) and WA (water activity) thresholds - such fluctuations were less abundant at the two other sites (Laguna Verda, Laguna Santa Rosa) than at the highest elevation. The group seen at Laguna Verde, starting from $\sim 7 \mathrm{pm}$ and ending between 3 and $10 \mathrm{am}$, is also visible here. Note the empty region between $\sim 11$ and $4 \mathrm{pm}$, when there seems to be no conditions for deliquescence. 
Total daily duration of ideal periods for deliquescence in Atacama

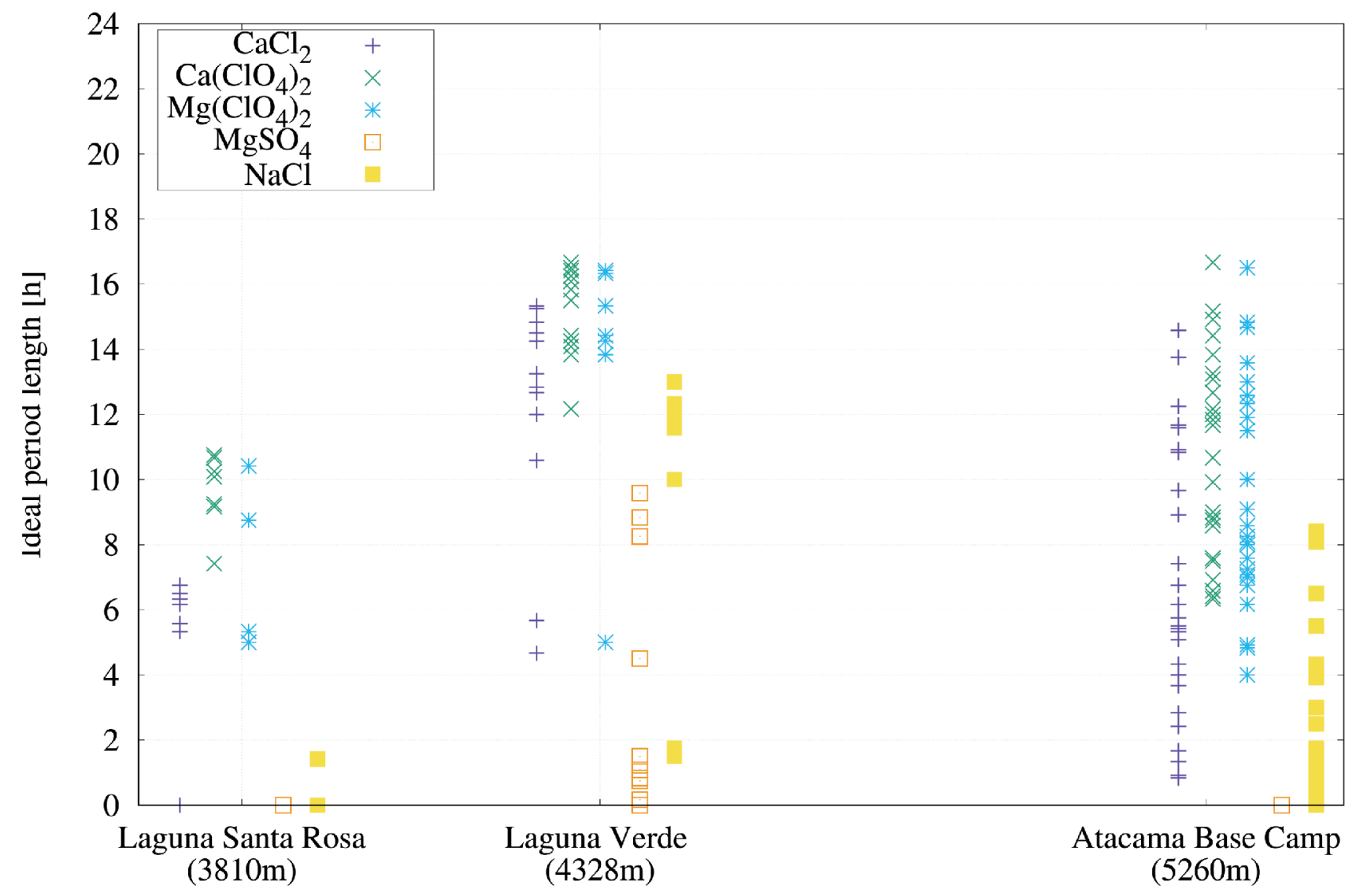

Fig. 6. The total amount of time when the circumstances were ideal for certain salts to liquefy through deliquescence (different salts marked by different symbols, see key at top right)

The $y$ axis shows the total length of ideal time per day. There were altogether 7 detectors, each of them positioned differently. Each symbol shows the total amount of ideal time for 1 specific salt at 1 specific detector summed for 1 day. The measurements spanned 1 day at Laguna Santa Rosa, 2 days at Laguna Verde and 4 days at the Atacama Base Camp

\section{DISCUSSION}

The $T / R H$ values at the different detectors, located close to each other at different altitudes, showed similar trends (see Fig. $4 \mathrm{~A})$. This implies that the small-scale $(\mathrm{cm})$ differences in the spatial distribution of rocks, and locations exposed or sheltered from the wind, did not overcome the analogue trends. Even below rocks at $1-3 \mathrm{~cm}$ depth, probably because of the constant wind, no substantial difference could be identified compared to the open air locations in the T/RH values recorded. This suggests that large differences $\left(>1-2^{\circ} \mathrm{C}\right.$ and $2.4 \%$ for $\left.R H\right)$ are not expected according to the local conditions at similar $\mathrm{cm}$-scale levels on Mars (above/next to/under cm-sized stones). However, due to the lower atmospheric density, and related smaller heat transport, on Mars, larger differences in TIRH parameters cannot be excluded and therefore need consideration there. The results also suggest that under Martian surface conditions, with even lower atmospheric pressure, relatively large fluctuations are expected in $T$ and $R H$ parameters, that the models cannot simulate yet (see below).

In agreement with the expectations, deliquescence seems to be possible under the hyperarid conditions of the Atacama Desert site analysed using only the available small water vapour content of the atmosphere. Similar trends were ob- served overall for the Atacama sites and modelling-based calculations for Mars. Night-time deliquescence was possible at all of these sites, and Mars-relevant salts considered are $\mathrm{CaCl}_{2}$, $\mathrm{Ca}\left(\mathrm{ClO}_{4}\right)_{2}, \mathrm{Mg}\left(\mathrm{ClO}_{4}\right)_{2}$ (supporting deliquescence for 10-12 $\mathrm{h}$ duration, almost all night long), while $\mathrm{Mg}(\mathrm{SO})_{4}$ and $\mathrm{NaCl}$ were less ideal for this process with shorter periods, and for $\mathrm{NaCl}$ no deliquescence may be present at all. This large difference between the specific salts points to the importance of hygroscopicity, what makes a difference in similar $T$ and $R H$ conditions. Although the few days covered by the on-site survey was not long enough to obtain statistically valid results relevant for annual durations, because of elevated $T$ and $R H$ fluctuations in day 3 at the Atacama Base Camp, the total duration of periods favourable for deliquescence was decreased by $30-40 \%$ and divided into separate periods. If such fluctuation also takes place on Mars, the modelling-based average results should be considered carefully.

These fluctuations increased along with increased elevation, what may not be solely related to the lower atmospheric pressure and air density (e.g., the decreased thermal inertia), because for example at the Atacama Base Camp on day 2 the fluctuations are substantially smaller in general than on day 1. These fluctuations were probably caused by atmospheric conditions, for example wind fluctuations. Wind can carry air masses with different temperatures from nearby locations, 

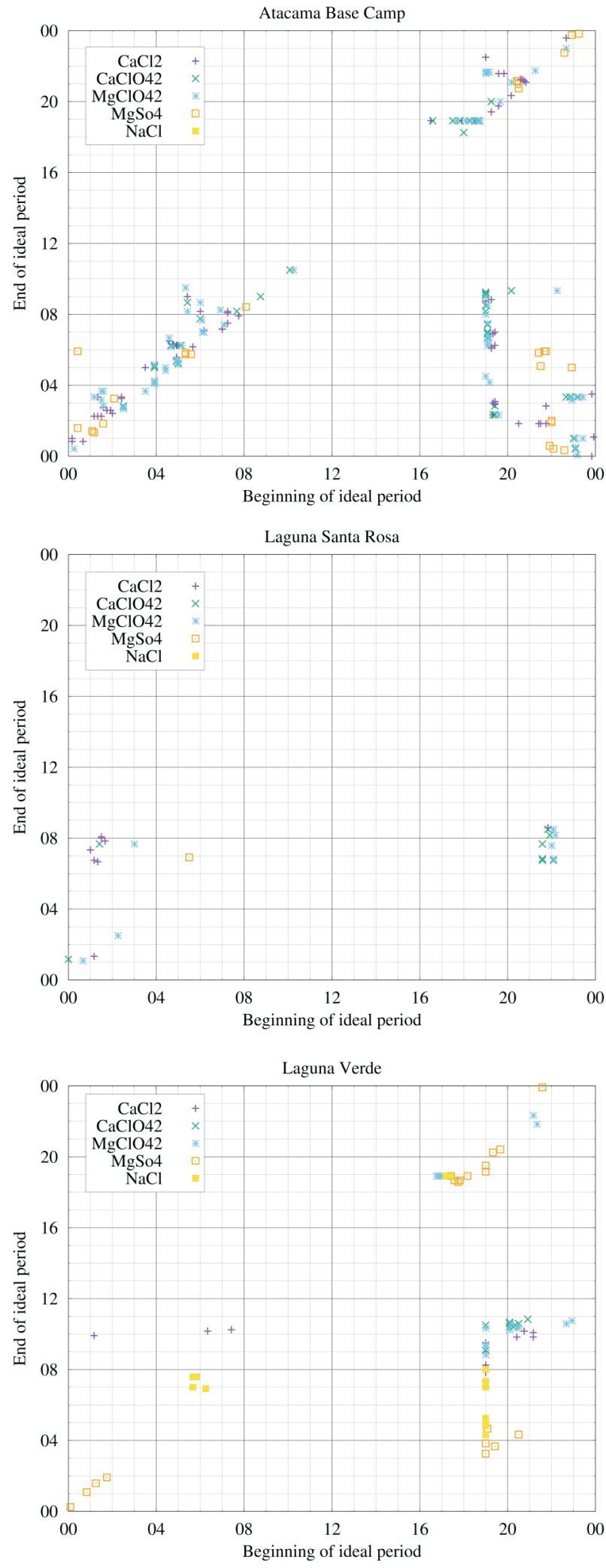

Fig. 7. The beginning and the end of each ideal time period for all of the salts analysed, separated by altitude (locations)

The beginnings and ends of ideal periods are denoted by differently shaped and coloured symbols according to the specific salts. The $x$ axis shows the beginning of the ideal time window, and the $y$ axis shows its end, both according to local time. Each point represents one interval of the specific salt at a given altitude which might have other surface temperatures because of different daytime exposure, albedo or thermal inertia. These factors are important as the small night-time temperature fluctuations produce relatively large fluctuations in relative humidity. These $R H$ values might fluctuate between being below and above the critical deliquescence relative humidity level on the same night - thus influencing the emergence of microscopic liquid, and this possibility should be targeted by future analysis.

As the altitude increases, the average temperature and the pressure decrease. With the atmosphere becoming more rarified at higher elevations, the total amount of water vapour that the atmosphere can potentially hold is decreased; however, it is still possible to reach high relative humidity values. There is a delicate balance between surface temperature and relative humidity values when it comes to ideal circumstances for deliquescence. Before the temperatures drop below the eutectic temperatures of the examined salts, the increasing altitude can result in longer ideal periods of deliquescence. We can see this if we compare the measurements recorded at Laguna Santa Rosa with Laguna Verde, but it is not as obvious if we compare Laguna Verde with Atacama Base Camp.

Based on the experience gained by this project, the next step could be the installation of a real deliquescence detector there, resembling the HABIT onboard ExoMars 2020 rover (Martin-Torres and Zorzano, 2018), which is proposed at lower altitude by Farris and Davila (2017).

\section{MARS-RELEVANT ASPECTS}

Atmospheric temperature variability, especially during evening hours (Hamilton et al., 2014), as well as daily variability in humidity (Martinez et al., 2016) was observed on Mars by the REMS instrument onboard Curiosity rover. Pressure fluctuations were also observed by Curiosity of up to $0.2 \mathrm{~Pa}$ in daytime and $1 \mathrm{~Pa}$ at night-time over a matter of seconds/minutes, possibly related to upslope/downslope winds. In the night, topographic slope winds contributed to producing simultaneous changes in surface temperature. Air temperatures fluctuated with amplitudes of $\sim 2 \mathrm{~K}$, while the ground temperature showed $0.2-0.5 \mathrm{~K}$ variations probably by forced convection (Ullán et al., 2017).

In Figure 8A we can see the daily surface temperature and relative humidity curves at Elysium Planitia, the landing site of the InSight mission. The boxes mark the beginnings and ends of the ideal periods for $\mathrm{Ca}\left(\mathrm{ClO}_{4}\right)_{2}$ to liquefy through deliquescence. The circumstances are ideal during the night, similar to what we can see in the Earth measurements above. The ideal time is expected to be continuous from $\sim 8 \mathrm{pm}$ until almost $11 \mathrm{pm}$. There is another short window just after $7 \mathrm{am}$. During the night, the surface temperature drops below the eutectic temperatures. In Figure 8B we can see another type of behaviour at the Phoenix landing site, Green Valley. Here both calcium perchlorate and magnesium perchlorate could liquify according to the model calculations. The ideal times are in the early morning hours from $\sim 5: 30$ am until 8:30 am, with a short ( $\sim 30$ minute) ideal window for magnesium perchlorate as well. The evening is ideal from $\sim 9 \mathrm{pm}$ extending to $\sim 11: 30 \mathrm{pm}$. The proposed ideal time for magnesium perchlorate is again $\sim 30$ minutes long in the evening.

The variations in temperature at the surveyed High Andes sites, concentrated between 10-16 local time, suggest that they might be related to strong solar insolation. A connection with local wind is also possible, but it is important to note that on calm days, the wind starts to blow in the afternoon, and on windy days there was continuous strong wind all day, but still stronger 


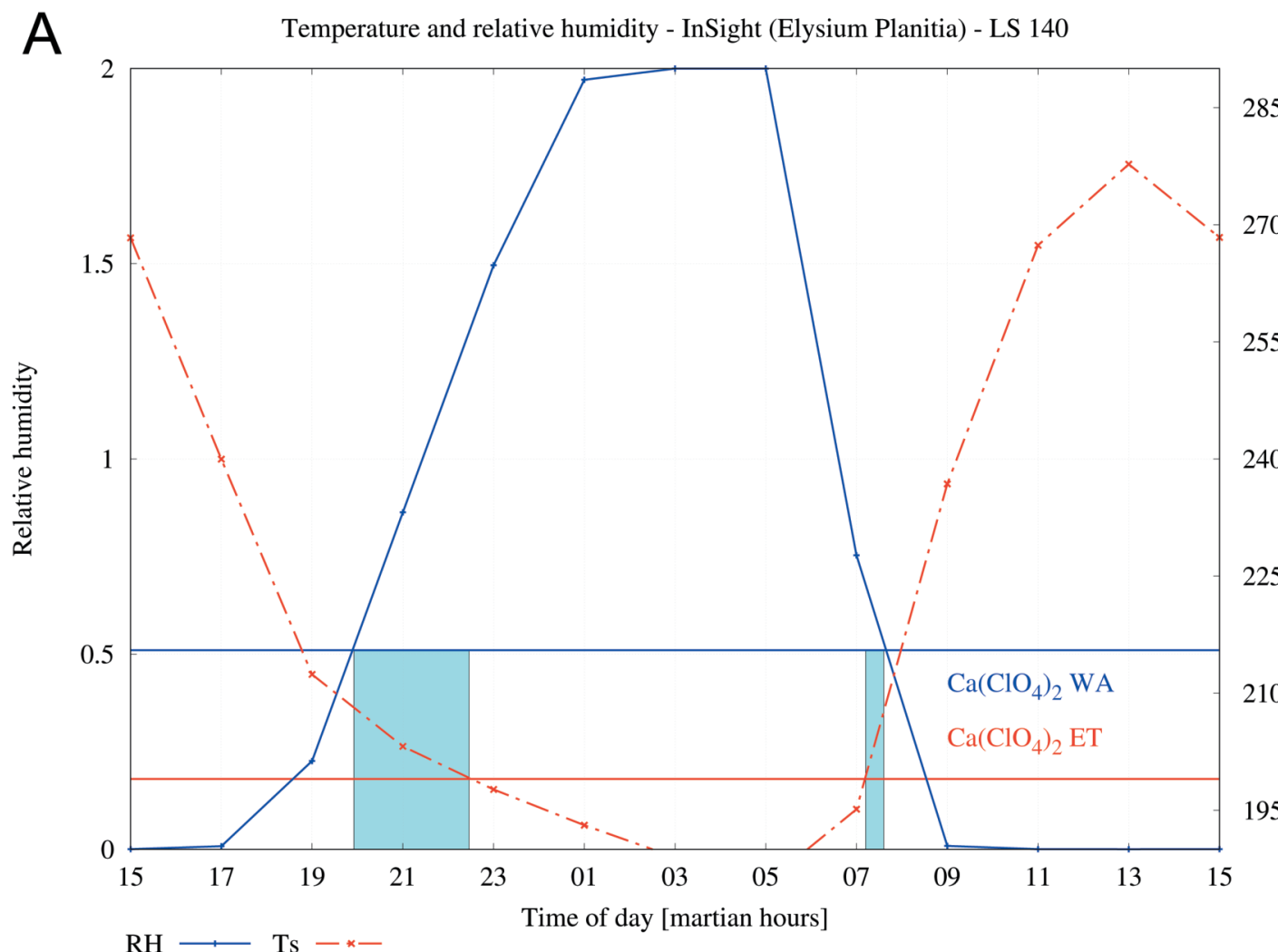

B

Temperature and relative humidity - Phoenix (Green Valley) - LS120

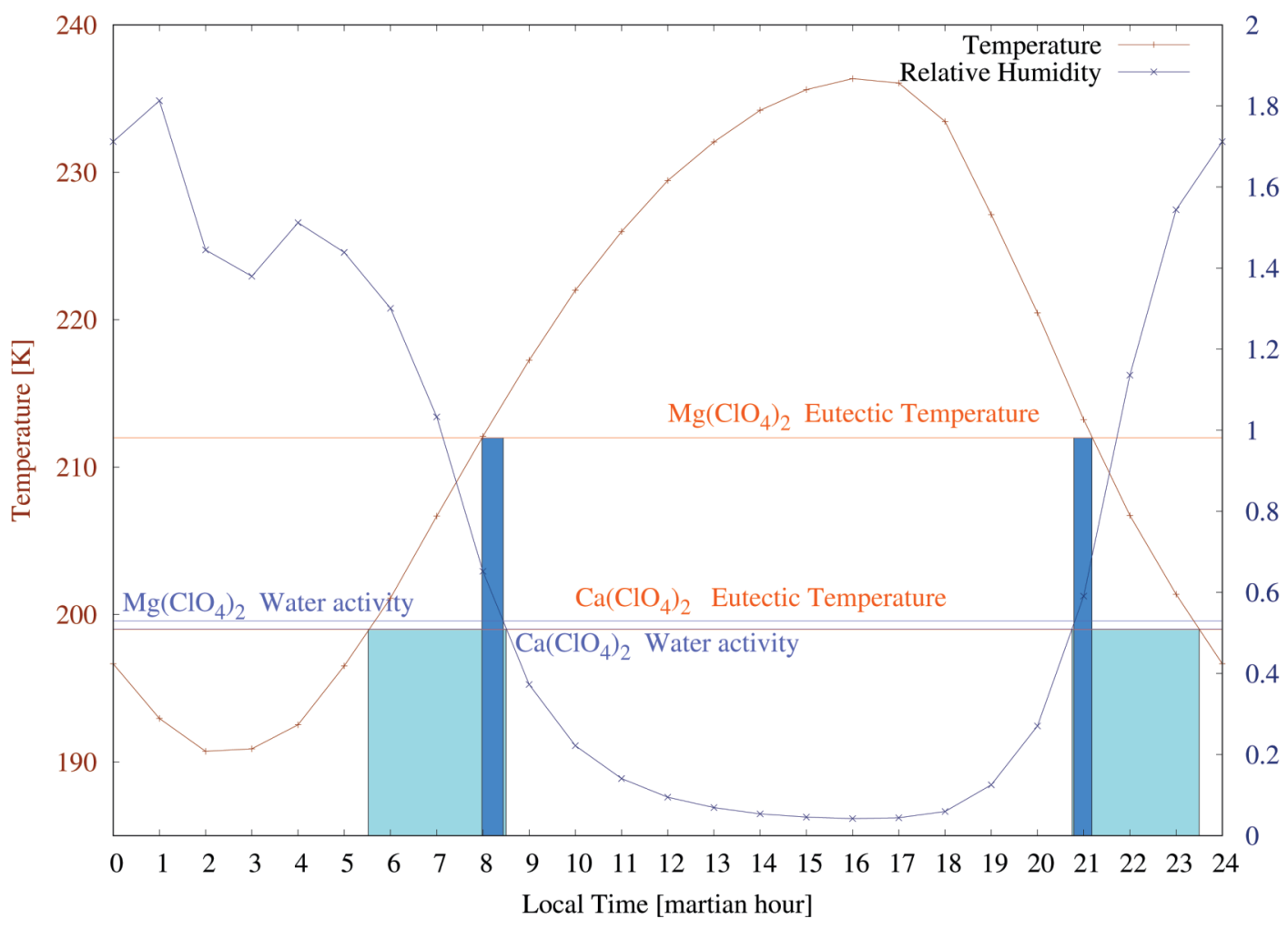

Fig. 8. Simulated daily surface temperature and relative humidity curves on Mars for comparison

The boxes mark the beginnings and ends of the ideal periods for $\mathrm{Ca}\left(\mathrm{ClO}_{4}\right)_{2}$ (light blue) and for $\mathrm{Mg}\left(\mathrm{ClO}_{4}\right)$ (dark blue) to liquefy through deliquescence. The landing site of InSight, Elysium Planitia is at the top (A) with Green Valley, the landing site of Phoenix rover at the bottom (B). The ideal times for deliquescence are denoted by blue rectangles. The minimum water activity and temperature levels with the name of the given salt are shown with horizontal lines 
Daily cycle of surface temperature and relative humidity

Horowitz Crater - Ls 333 and Atacama base camp - Day 3

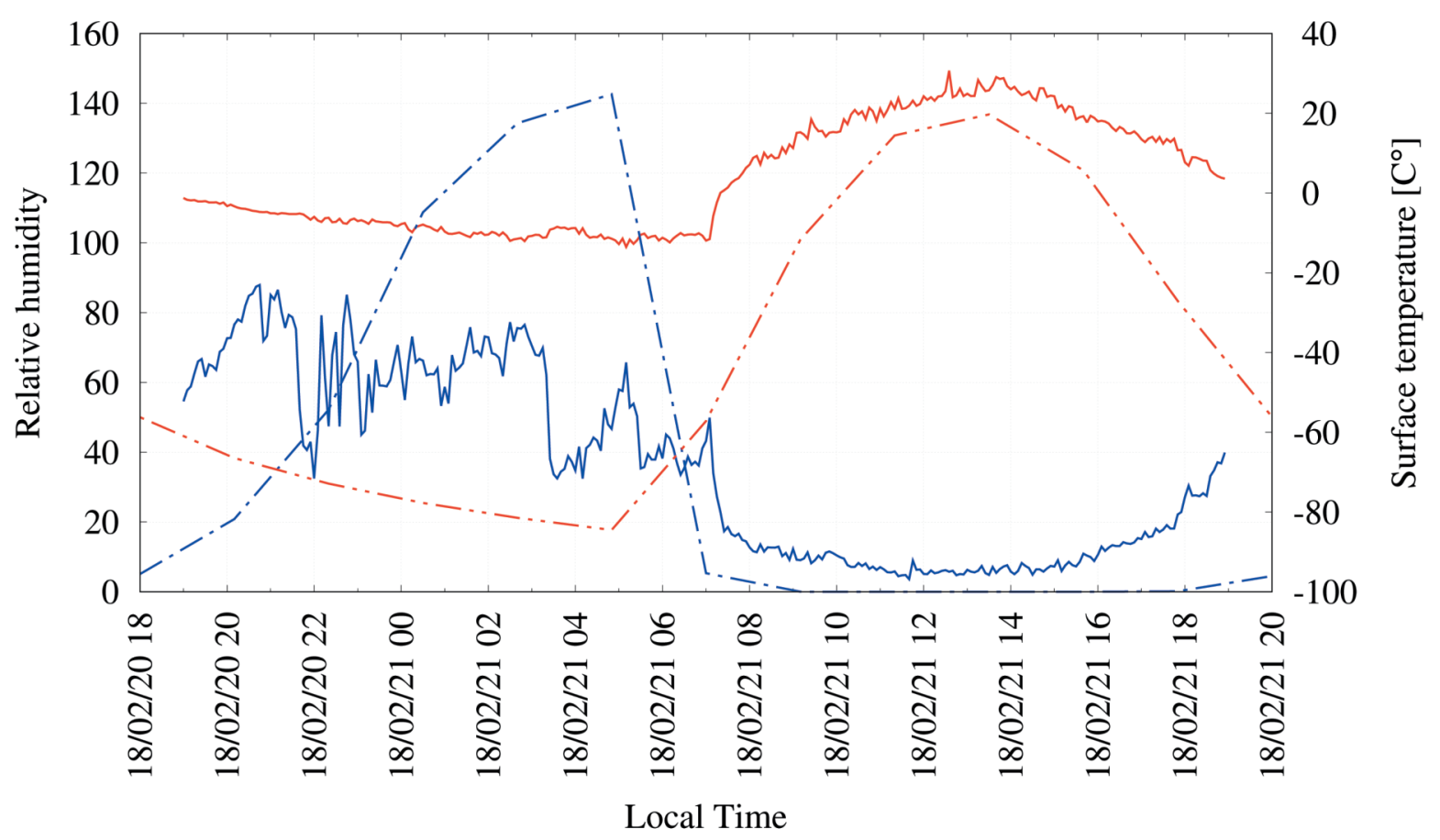

Daily cycle of surface temperature and relative humidity Newton Basin - Ls 333 and Atacama base camp - Day 2

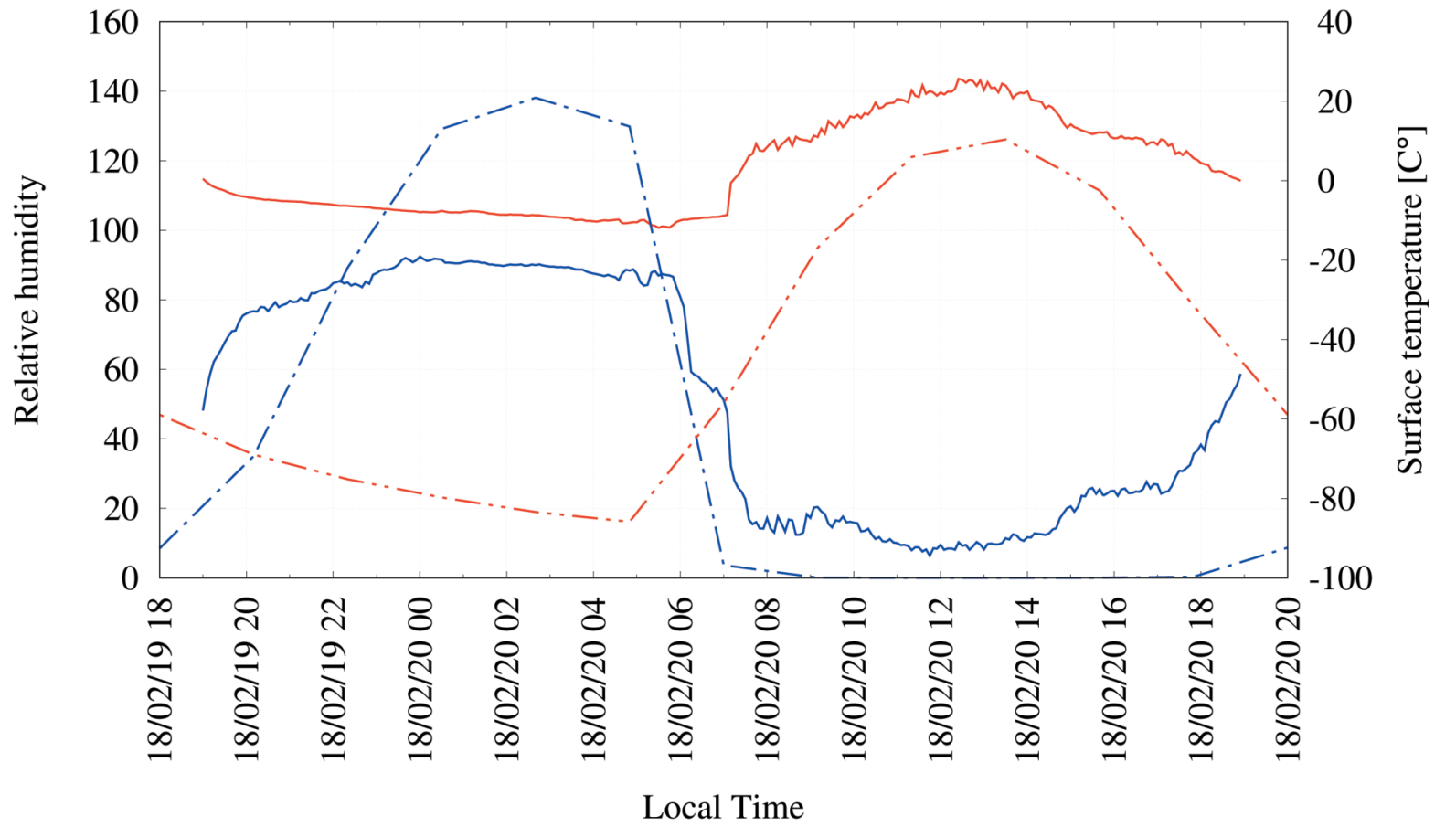

Fig. 9. Comparison between the daily surface temperature (red) and relative humidity (blue) curves at the Atacama Base Camp (dashed lines) and two RSL sites in Horowitz Crater and Newton Basin (solid lines) on Mars

At the top there is an example for markedly fluctuating relative humidity levels $(\mathbf{A})$, while at the bottom there is one for a mostly constant night-time relative humidity $(\mathbf{B})$; the overall trends of the curves are similar, but the simulated Martian values show greater daily variations, as expected 
in the afternoon. Thus it is not likely that the wind would be the main reason for the fluctuations on Earth.

In Figure 9 there is a comparison between the Atacama Base Camp measurements and model calculated values at two recurring slope lineae (RSL) sites (McEwen et al., 2011) on Mars. These RSL-s are dark features on the surface of Mars that were previously considered as evidence for liquid subsurface flow of water due to their changes in shape and colour. New research interprets them as possible granular flows, where the slope is steep enough for grains of dust and sand to slide down (Dundas et al., 2017). The question of whether the RSL are caused by granular flows or liquid water/brine activity is still under debate today. The overall trends are similar, but the simulated Martian results show greater daily variations in both cases, as expected. The Martian curves have a 1 hour temporal resolution, and they were calculated by the LMDZ GCM detailed in Forget et al. (1999), including a water cycle (Navarro et al., 2014). The relative humidity values were determined as described in Pal and Kereszturi (2017). Both the daily temperature and relative humidity fluctuations are much larger on Mars, but small-scale fluctuations are visible only on Earth as the Martian dataset cannot modelthe process on this scale. Such fluctuations obviously could influence the temporal behaviour of deliquescence, as it could exist on Mars, even though the model data (Fig. 9) is not able to show it.

Although the pressure and temperature conditions barely overlap between Mars and these Earth locations, the style of $T / R H$ fluctuation from the Atacama region point to conditions and processes that might be relevant for Mars. For example the $R H$ values on Mars at the Phoenix landing site were close to $\sim 0 \%$ at $-13.5^{\circ} \mathrm{C}$ daytime (Farris et al., 2017), but thus correspond with the lowest temperature recorded at the Atacama Base Camp. The temporal behaviour shows relevance between the two planets (very dry daytime and occasionally saturated night-time), though the actual values did not overlap.

The importance and Mars relevance of the T/RH behaviour at the site analysed is its high elevation that produced large daily fluctuations, close to saturation, even in an otherwise dry region (similar to Mars, where the $60-100^{\circ} \mathrm{C}$ daily fluctuation could result in close-to-saturation conditions despite the low total water vapour abundance). Another important analogue aspect is the high variability, down to several minutes, that was also partly observed on Mars by the REMS instrument onboard the Curiosity rover, though this is not yet involved in the atmospheric models describing the Martian near-surface conditions.

Further analogue aspects of the analysed High Andes Atacama site make it important for Mars-relevant analogue work on the Earth in the future. Besides the general dryness and decreased atmospheric pressure plus elevated UV irradiation, is the occurrence of permafrost (ground with temperatures $<0 \mathrm{C}^{\circ}$ for at least two consecutive years; van Everdingen, 2005) in patchy distribution $>5200 \mathrm{~m}$ and continuously $>5600 \mathrm{~m}$ (Nagy et al., 2019). The permafrost is accompanied by some post-volcanic activity there (Moreno and Gibbons, 2007) while some glaciers also existed there until recently (Oyarzun, 1987).
These characteristics, together with the conditions to analyse the occurrence of liquid water in the form of deliquescence, make this site highly Mars-relevant.

\section{CONCLUSIONS}

1. During the field work at the Ojos del Salado mountainous region in the High Andes Atacama area, temperature and relative humidity measurements were made with detectors exposed on the surface and next to or below some rocks, in order to identify night-time changes in temperature and relative humidity values. The exact placement of the detectors did not influence the measurements as much as did the changing of overall weather conditions, and small-scale micro- or nanoclimate observations are worth making on Mars, as the differences in $T / R H$ parameters could be larger there because of the lower atmospheric density and related reduced heat transport possibility. The patterns recorded showed characteristic daily cycles with decreased temperature and elevated relative humidity during the night; however, due to weather changes, differences between certain days could be also observed. The overall behaviour and daily trends of relative humidity and surface temperatures, along with the possible ideal time windows, show overlap between the Atacama Desert and the Martian sites analysed.

2. Strong fluctuation could be observed at 10-20 minute-long temporal scales in the temperature and relative humidity values, that was not present in the Martian model-based datasets, thus any future detectors should be prepared to witness such fluctuations on Mars. Considering different Mars-relevant salts, the longest duration for deliquescence (between 7 and 12 hours in a night) was found in the case of $\mathrm{CaCl}_{2}$, $\mathrm{Ca}\left(\mathrm{ClO}_{4}\right)_{2}$ and $\mathrm{Mg}\left(\mathrm{ClO}_{4}\right)_{2}$ salts. $\mathrm{MgSO}_{4}$ salt provided the shortest period, while with $\mathrm{NaCl}$ salt almost no period favourable for deliquescence was found.

3. The ideal duration for deliquescence showed some increase with the rising elevation, because of the decreasing night-time temperature resulted in larger relative humidity values. This observation supports the expectations that despite the low humidity on Mars, the very low night-time temperatures could provide the necessary conditions for deliquescence. The locations surveyed in the High Andes desert provide interesting conditions for more detailed analysis of the deliquescence process on Mars in the future, including testing of instruments to identify the emergence of liquids, as projected for the HABIT instrument onboard ExoMars 2020 rover mission.

Acknowledgements. The fieldwork, done by A. Kereszturi, was supported by the COOP NN 116927 project; some instrument-related aspects and the numerical analysis were supported by the GINOP-2.3.2-15-2016-00003 grant of the Hungarian National Research, Development and Innovation Office (NKFIH). The Martian modelling done by B. Pal was supported by the EXODRILTECH project of ESA. The comments by the journal reviewers are appreciated. 


\section{REFERENCES}

Ahumada, A.L., 2002. Periglacial phenomena in the high mountains of northwestern Argentina. South African Journal of Science, 98: 166-170.

Ammann, C., Jenny, B., Kammer, K., Messerli, B., 2001. Late Quaternary glacier response to humidity changes in the arid Andes of Chile (18-29 $\mathrm{S}$ ). Palaeogeoraphy Palaeoclimatology Palaeoecology, 172: 313-326.

Azócar, G.F, Brenning, A., 2010. Hydrological and geomorphological significance of rock glaciers in the dry Andes, Chile (27-33 S). Permafrost and Periglacial Processes, 21: 42-53.

Amundson, R., Barnes, J.D., Ewing, S., Heimsath, A., Chong, G., 2012. The stable isotope composition of halite and sulfate of hyperarid soils and its relation to aqueous transport. Geochimica and Cosmochimica Acta, 99: 271-286.

Artieda, O., Davila, A., Wierzchos, J., Buhler, P., Rodríguez Ochoa, R., Carmen Ascaso, J., 2015. Surface evolution of salt-encrusted playas under extreme and continued dryness. Earth Surface Processes and Landforms, 40: 1939-1950.

Azócar, G.F., Brenning, A., 2010. Hydrological and geomorphological significance of rock glaciers in the dry Andes, Chile (27-33ㅇ). Permafrost et Periglacial Processes, 21: 42-53.

Azua-Bustos, A., Caro Lara, L., Vicuña, R., 2015. Environmental Microbiology Reports, 7: 388-394.

Azua-Bustos, A., Fairén, A.G., González-Silva, C., Ascaso, C. Carrizo, D., Fernández-Martínez, M.Á., Fernández-Sampedro, M., García-Descalzo, L., García-Villadangos, M., Martin-Redondo, M.P., Sánchez-García, L., Wierzchos, J., Parro, V., 2018. Unprecedented rains decimate surface microbial communities in the hyperarid core of the Atacama Desert. Scientific Reports, 8, id. 16706.

Boynton, W.V., Ming, D.W., Kounaves, S.P., Young, S.M.M., Arvidson, R.E., Hecht, M.H., Hoffman, J., Niles, P.B., Hamara, D.K., Quinn, R.C., Smith, P.H., Sutter, B., Catling, D.C., Morris, R.V., 2009. Evidence for calcium carbonate at the Mars Phoenix Landing Site. Science, 335: 61-64.

Cabrol, N.A., Grin, E.A., 1999. Distribution, classification, and ages of Martian impact crater lakes. Icarus, 142: 160-172.

Catling, D.C., Claire, M.W., Zahnle, K.J., Quinn, R.C., Clark, B.C., Hecht, M.H., Kounaves, S., 2010. Atmospheric origins of perchlorate on Mars and in the Atacama. Journal of Geophysical Research, 115: CiteID E00E11.

Chevrier, V.F., Rivera Valentin, E.G., 2012. Formation of recurring slope lineae by liquid brines on present day Mars. Geophysical Research Letters, 39: L21202.

Clapperton, C.M., 1994. The Quaternary glaciation of Chile. Revista Chilena de Historia Natural, 67: 369-383.

Cobos, D., Corte, A., 1990. Geocryological observations in Ojos del Salado, Central Andes, Lat. 27\%. IGCP/UNESCO Project 297, 2nd Meeting, Geocryology of Southern Africa, Rhodes University, Grahamstown.

Czechowski, L., Witek, P., Misiura, K., 2013. Dynamical model of rivers on Mars. European Planetary Science Congress, abstract EPSC2013-917.

Davila, A.F., Duport, L.G., Melchiorri, R., Jänchen, J., Valea, S., de los Rios, A., Fairén, A.G., Möhlmann, D., McKay, C.P., Ascaso, C., Wierzchos, J., 2010. Hygroscopic salts and the potential for life on Mars. Astrobiology, 10: 617-628.

Dundas, C.M., McEwen, A.S., Chojnacki, M., Milazzo, M.P., Byrne, S., McElwaine, J.N., Urso, A., 2017. Granular flows at recurring slope lineae on Mars indicate a limited role for liquid water. Nature Geoscience, 10: 903-907

EhImann, B.L., Swayze, G.A., Milliken, R.E., Mustard, J.F., Clark, R.N., Murchie, S.L., Breit, G.N., Wray, J.J., Gondet, B., Poulet, F., Carter, J., Calvin, W.M., Benzel, W.M., Seelos, K.D., 2016. Discovery of alunite in Cross crater, Terra Sirenum, Mars: evidence for acidic, sulfurous waters. American Mineralogist, 101: 1527.
Farris, H.N., Davila, Al., 2016. Deliquescence-driven brine formation in the Atacama Desert, Chile. 47th Lunar and Planetary Science Conference, abstract 2518.

Farris, H.N., Davila, A., 2017. Calcium perchlorate brine formation in the Atacama desert, Chile and implications for liquid water at the surface of Mars. Astrobiology Science Conference, abstract no. 3483.

Farris, H.N., Conner, N.B., Chevrier, V.F., Rivera-Valentin, E.G., 2017. Adsorption driven regolith-atmospheric water vapor transfer on Mars: an analysis of Phoenix TECP data. Icarus, 308: $71-75$.

Fassett, C.I., Head, J.W., 2008. Valley network-fed, open-basin lakes on Mars: distribution and implications for Noachian surface and subsurface hydrology. Icarus, 198: 37-56.

Forget, F., Hourdin, F., Fournier, R., Hourdin, C., Talagrand, O., Collins, M., Lewis, S.R., Read, P.L., Huot, J.-P., 1999. Improved general circulation models of the Martian atmosphere from the surface to above $80 \mathrm{~km}$. Journal of Geophysical Research, 104: 24155-24176.

Glavin, D.P., Freissinet, C., Miller, K.E., Eigenbrode, J.L., Brunner, A.E., Buch, A., Sutter, B., Archer, P.D., Atreya, S.K., Brinckerhoff, W.B., Cabane, M., Coll, P., Conrad, P.G., Coscia, D., Dworkin, J.P., Franz, H.B., Grotzinger, J.P., Leshin, L.A., Martin, M.G., McKay, C., Ming, D.W., Navarro González, R., Pavlov, A., Steele, A., Summons, R.E., Szopa, C., Teinturier, S., Mahaffy, P.R., 2013. Evidence for perchlorates and the origin of chlorinated hydrocarbons detected by SAM at the Rocknest aeolian deposit in Gale Crater. Journal of Geophysical Research, 118: id. 20144.

Gough, R.V., Primm, K.M., Rivera-Valentín, E.G., Martínez, G.M., Tolbert, M.A., 2019. Solid-solid hydration and dehydration of Mars-relevant chlorine salts: Implications for Gale Crater and RSL locations. Icarus, 321: 1-13.

Gough, R.V., Chevrier, V.F., Baustian, K.J., Wise, M.E., Tolbert, M.A., 2011. Laboratory studies of perchlorate phase transitions: Support for metastable aqueous perchlorate solutions on Mars. Earth and Planetary Science Letters, 312: 371-377.

Gspurning, J., Lazer, R., Sulzer, W., 2006. Regional climate and snow/glacier distribution in Southern Upper Atacama (Ojos del Salado) - an integrated statistical, GIS and RS based approach. Grazer Schriften der Geographie and Raumforschung, 41: 59-70.

Hamilton, V.E., Vasavada, A.R., Sebastián, E., Torre Juárez, M., Ramos, M., Armiens, C., Arvidson, R.E., Carrasco, I., Christensen, P.R., De Pablo, M.A., Goetz, W., Gómez-Elvira, J., Lemmon, M.T., Madsen, M.B., Martín-Torres, F.J., Martínez-Frías, J., Molina, A., Palucis, M.C., Rafkin, S.C.R., Richardson, M.I., Yingst, R.A., Zorzano, M.-P., 2014. Observations and preliminary science results from the first 100 sols of MSL Rover Environmental Monitoring Station ground temperature sensor measurements at Gale Crater. Journal of Geophysical Research, 119: 745-770.

Hecht, M.H., Kounaves, S.P., Quinn, R.C., West, S.J., Young, S.M.M., Ming, D.W., Catling, D.C., Clark, B.C., Boynton, W.V., Hoffman, J., DeFlores, L.P., Gospodinova, K., Kapit, J., Smith, P.H., 2009. Detection of perchlorate and the soluble chemistry of Martian soil at the phoenix lander site. Science, 325: 64 .

Heldmann, J.L., Conley, C.A., Brown, A.J., Fletcher, L., Bishop, J.L., McKay, C.P., 2010. Possible liquid water origin for Atacama Desert mudflow and recent gully deposits on Mars. Icarus, 206: 685-690.

Jackson, W.A., Böhlke, J.K., Andraski, B.J., Fahlquist, L., Bexfield, L., Eckardt, F.D., Gates, J.B., Davila, A.F., McKay, C.P., Rao, B., Sevanthi, R., Rajagopalan, S., Estrada, N., Sturchio, N., Hatzinger, P.B., Anderson, T.A., Orris, G., Betancourt, J., Stonestrom, D., Latorre, C., Li, Y., Harvey, G.J., 2015. Global patterns and environmental controls of per- 
chlorate and nitrate co-occurrence in arid and semi-arid environments. Geochimica et Cosmochimica Acta, 164: 502-522.

Jackson, W.A., Böhlke, J.K., Andraski, B.J., Fahlquist, L., Bexfield, L., Eckardt, F.D., Gates, J.B., Davila, A.F., McKay, C.P., Rao, B., Sevanthi, R., Rajagopalan, S., Estrada, N., Sturchio N., Hatzinger, P.B., Anderson, T.A., Orris, G., Betancourt, J., Stonestrom, D., Latorre, C., Li, Y., Harris, J.K., Cousins, C.R., Claire, M.W., 2016. Spectral identification and quantification of salts in the Atacama Desert. Proceedings of the SPIE 10005: id. 100050l.

Kate, I.L., 2018. Organic molecules on Mars. Science, 360 1068-1069

Hecht, M.H., Kounaves, S.P., Quinn, R.C., West, S.J., Young, S.M.M., Ming, D.W., Catling, D.C., Clark, B.C., Boynton, W.V., Hoffman, J., DeFlores, L.P., Gospodinova, K., Kapit, J. Smith, P.H., 2009. Detection of perchlorate and the soluble chemistry of Martian soil at the phoenix lander site. Science, 325: 64 .

Kereszturi, A., 2019. Unique and potentially Mars relevant flow regime and water sources at a High-Andes Atacama site. Astrobiology, 20: 723-740.

Kereszturi, A., Rivera-Valentin, E.G., 2012. Locations of thin liquid water layers on present-day Mars. Icarus, 221: 289-295.

Kereszturi, A., Rivera-Valentin, E.G., 2016. Possible water lubricated grain movement in the circum-polar region of Mars. Planetary Space Science, 125: 130-146.

Kereszturi, A., Aszalós, J., Heiling, B., Kapui, Zs., Kiraly, Cs., Leél-Össy, Sz., Nagy, B., Pal, B., Skulteti, A., Szalai, Z., 2019. Cold, dry, windy, and UV irradiated: surveying Mars-relevant conditions in Ojos del Salado Volcano (Andes Mountains, Chile). Astrobiology, 20: 677-683.

Kounaves, S.P., Hecht, M.H., Kapit, J., Gospodinova, K., DeFlores, L., Quinn, R.C., Boynton, W.V., Clark, B.C., Catling, D.C. Hredzak, P., Ming, D.W., Moore, Q., Shusterman, J., Stroble, S., West, S.J., Young, S.M.M., 2010. Wet chemistry experiments on the 2007 Phoenix Mars Scout Lander mission: data analysis and results. Journal of Geophysical Research, 115 E00E10.

Lewis, S.R., 2003. Modelling the martian atmosphere. Astronomy and Geophysics, 44: 4.6-4.14.

Losiak, A., Czechowski, L., Velbel, M.A., 2015. Ephemeral liquid water at the surface of the martian North Polar Residual Cap: results of numerical modelling. Icarus, 262: 131-139.

Martin-Torres, J., Zorzano, M.-P., 2018. The instrument HABIT (HabitAbility, Brine Irradiation and Temperature) on the ExoMars platform. 42nd COSPAR Scientific Assembly, Abstract id. F3.3-6-18.

Martin-Torres, F.J., Zorzano, M.-P., Valentin-Serrano, P., Harri, A.M., Genzer, M., Kemppinen, O., Rivera-Valentin, E.G., Wray, J., Bo Madsen, M., Goetz, W., McEwen, A.S., Hardgrove, C., Renno, N., Chevrier, V.F., Mischna, M., Navarro-Gonzalez, R., Martinez-Frias, J., Conrad, P., McConnochie, T., Cockell, C., Berger, G., Vasavada, A., Sumner, D., Vaniman, D., 2015. Transient liquid water and water activity at Gale Crater on Mars. Nature Geoscience, 8: 357-361.

Martinez, G., McConnochie, T., Renno, N., Meslin, P.-Y., Fischer, E., Vicente-Retortillo, A., Borlina, C., Kemppinen, O., Genzer, M., Harri, A.-M., de la Torre-Juárez, M., Zorzano, M.-P., Martin-Torres, J., Bridges, N., Maurice, S., Gasnault, O., Gomez-Elvira, J., Wiens, R., 2016. Diurnal variation of atmospheric water vapor at Gale crater: analysis from ground-based measurements. EGU General Assembly, abstract EPSC2016-9297.

Martínez, G.M., Newman, C.N., De Vicente-Retortillo, A., Fischer, E., Renno, N.O., Richardson, M.I, Fairén, A.G., Genzer, M., Guzewich, S.D., Haberle, R.M., Harri, A.M. Kemppinen, O., Lemmon, M.T., Smith, M.D., de la TorreJuárez, M., Vasavada, A.R., 2017. The modern near-surface Martian climate: a review of in-situ meteorological data from Viking to Curiosity. Space Science Reviews, 212: 295-338.

McEwen, A.S., Ojha, L., Dundas, C.M., Mattson, S.S., Byrne, S., Wray, J.J., Cull, S.C., Murchie, S.L., Thomas, N., Gulick,
V.C., 2011. Seasonal flows on warm Martian slopes. Science, 333: 740 .

McKay, C.P., Friedmann, E.I., Gómez-Silva, B., CáceresVillanueva, L., Andersen, D.T., Landheim, R., 2003. Temperature and moisture conditions for life in the extreme arid region of the Atacama Desert: four years of observations including the $\mathrm{El}$ NiZo of 1997-1998. Astrobiology, 3: 393-406.

McKay, L., Claire, M., 2016. The presence and distribution of salts as a palaeoprecipitation proxy in Atacama soils. EGU General Assembly, abstract EPSC2016-212.

Montgomery, W., Jaramillo, E.A., Royle, S.H., Kounaves, S.P., Schulze-Makuch, D., Sephton, M.A., 2019. Effects of oxygen-containing salts on the detection of organic biomarkers on Mars and in terrestrial analog soils. Astrobiology, 19: 711-721.

Moreno, T., Gibbons, W., 2007. The Geology of Chile. Geological Society London.

MöhImann, D., Thomsen, K., 2011. Properties of cryobrines on Mars. Icarus, 212: 123-130.

Nagy, B., Mari, L., Kovács, J., Nemerkényi, Zs., Heiling, Zs. 2014a. Environment changes in the Dry Andes - monitoring research on the Ojos del Salado (in Hungarian). In: HUNGEO 2014 Magyar Földtudományi (eds. T. Cserny, P. Kovács-Pálffy and Á. Krivánné Horváth): 53-62. 1103 szakemberek XII. találkozója. Budapest: Magyarhoni Földtani Társulat.

Nagy, B., Mari, L., Kovács, J., Nemerkényi, Zs., Heiling, Zs. 2014b. Data from the subsurface of a high-mountain desert: water and ice on the Ojos del Salado (in Hungarian), Egyetem Meteorológiai Füzetek - Meteorological Notes of Universities, 25:123-128.

Nagy, B., Ignéczi, A., Kovács, J., Szalai, Z., Mari, L., 2019. Shallow ground temperature measurements on the highest volcano of the Earth, the Mt. Ojos del Salado, Arid Andes, Chile. Permafrost and Periglacial Processes, 30: 3-18.

Navarro, T., Madeleine, J.-B., Forget, F., Spiga, A., Millour, E., Montmessin, F., Määttänen, A., 2014. Global climate modeling of the Martian water cycle with improved microphysics and radiatively active water ice clouds. Journal of Geophysical Research, 119: 1479-1495.

Navarro-González, R., Rainey, F.A., Molina, P., Bagaley, D.R., Hollen, B.J., de la Rosa, J., Small, A.M., Quinn, R.C., Grunthaner, F.J., Cáceres, L., Gomez-Silva, B., McKay, C.P., 2003. Mars-like soils in the Atacama Desert, Chile, and the dry limit of microbial life. Science, 302: 1018-1021.

Nikolakakos, G., Whiteway, J.A., 2018. Laboratory study of adsorption and deliquescence on the surface of Mars. Icarus, $\mathbf{3 0 8}$ : 221-229.

Nuding, D.L., Rivera Valentin, E.G., Davis, R.D., Gough, R.V., Chevrier, V.F., Tolbert, M.A., 2014 Deliquescence and efflorescence of calcium perchlorate: An investigation of stable aqueous solutions relevant to Mars. Icarus, 243: 420-428.

Oyarzun, C.G., 1987. Inventario de Glaciares de los Andes Chilenos desde los 180 a los 320 de Latitud Sur. Revista de Geografía Norte Grande, 14: 35-48.

Ojha, L., Wilhelm, M.B., Murchie, S.L., McEwen, A.S., Wray, J.J., Hanley, J., Massé, M., Chojnacki, M., 2015. Spectral evidence for hydrated salts in recurring slope lineae on Mars. Natural Geoscience, 8: 829-832.

Óscar, G.F., 1995. Volcanes de Chile (in Spanish). Instituto Geográfico Militar Yearbook, Santiago, Chile.

Osterloo, M.M., Hamilton, V.E., Bandfield, J.L., Glotch, T.D., Baldridge, A.M., Christensen, P.R., Tornabene, L.L., Anderson, F.S., 2008. Chloride-bearing materials in the southern highlands of Mars. Science, 319: 1651-1654.

Oyarzun, C.G., 1987. Inventario de Glaciares de los Andes Chilenos desde los 180 a los 320 de Latitud Sur. Revista de Geografía Norte Grande, 14: 35-48.

Pal, B., Kereszturi, A., 2017. Possibility of microscopic liquid water formation at landing sites on Mars and their observational potential. Icarus, 282: 84-92.

Primm, K.M., Gough, R.V., Wong, J., Rivera Valentin, E., Martinez, G.M., Hogancamp, J.V., Archer, P.D., Ming, D.W., Tolbert, M.A., 2018. The effect of Mars relevant soil analogs on 
the water uptake of magnesium perchlorate and implications for the near surface of Mars. Journal of Geophysical Research, 123: 2076-2088.

Reiss, D., Erkeling, G., Bauch, K.E., Hiesinger, H., 2010. Evidence for present day gully activity on the Russell crater dune field, Mars. Geophysical Research Letters, 37: L06203.

Renno, N.O., Bos, B.J., Catling, D., Clark, B.C., Drube, L., Fisher, D., Goetz, W., Hviid, S.F., Keller, H.U., Kok, J.F., Kounaves, S.P., Leer, K., Lemmon, M., Madsen, M.B., Markiewicz, W.J., Marshall, J., McKay, C., Mehta, M., Smith, M., Zorzano, M.P., Smith, P.H., Stoker, C., Young, S.M.M., 2009. Possible physical and thermodynamical evidence for liquid water at the Phoenix landing site. Journal of Geophysical Research, 114 E00E03.

Rivera Valentín, E.G., Gough, R.V., Chevrier, V.F., Primm, K.M., Martínez, G.M., Tolbert, M., 2018. Constraining the potential liquid water environment at Gale Crater, Mars. Journal of Geophysical Research, 123: 1156-1167.

Smith, M.L., Claire, M.W., Catling, D.C., Zahnle, K.J., 2014. The formation of sulfate, nitrate and perchlorate salts in the martian atmosphere. Icarus, 231: 51-64.

Stepinski, T.F., Stepinski, A.P., 2005. Morphology of drainage basins as an indicator of climate on early Mars. Journal of Geophysical Research, 110 (E12): CitelD E12S12.

Tokano, T., 2005. Water on Mars and Life. Springer.

Toner, J.D., Catling, D.C., Light, B., 2014a. The formation of supercooled brines, viscous liquids, and low-temperature perchlorate glasses in aqueous solutions relevant to Mars. Icarus, 233: $36-47$

Toner, J.D., Catling, D.C., Light, B., 2014b. Soluble salts at the Phoenix Lander site, Mars: a reanalysis of the wet chemistry laboratory data. Geochimica et Cosmochimica Acta, 136: 142-168.

Toner, J.D., Catling, C.D., Light, B., 2015a. Modeling salt precipitation from brines on Mars: evaporation versus freezing origin for soil salts. Icarus, 250: 451-461.
Toner, J.D., Catling, D.C., Light, B., 2015b. A revised Pitzer model for low-temperature soluble salt assemblages at the Phoenix site, Mars. Geochimica et Cosmochimica Acta, 166: 327-343.

Toner, J.D., Catling, D.C., Light, B., 2015b. A revised Pitzer model for low-temperature soluble salt assemblages at the Phoenix site, Mars. Geochimica et Cosmochimica Acta, 166: 327-343.

Martin-Torres, F.J., Zorzano, M.-P., Valentin-Serrano, P., Harri, A.-M., Genzer, M., Kemppinen, O., Rivera-Valentin, E.G., Jun, I., Wray, J., Bo Madsen, M., Goetz, W., McEwen, A.S., Hardgrove, C., Renno, N., Chevrier, V.F., Mischna, M., NavarroGonzalez, R., Martinez-Frias, J., Conrad, P., McConnochie, T., Cockell, C., Berger, G., Vasavada, A., Sumner, D., Vaniman, D., 2015. Transient liquid water and water activity at Gale crater on Mars. Nature Geoscience, 8: 357-361.

Ullán, A., Zorzano, M.-P., Martín-Torres, J., Valentín-Serrano, P., Kahanpää, H., Harri, A.-M., Gómez-E., J., Navarro, S., 2017. Analysis of wind-induced dynamic pressure fluctuations during one and a half Martian years at Gale Crater. Icarus, 288: 78-87.

van Everdingen, R. ed., 2005. Multi-language glossary of permafrost and related ground-ice terms. Boulder, CO: National Snow and Ice Data Center/World Data Center for Glaciology.

Weng, M., Millan, M., Zaikova, E., Bevilacqua, J., Johnson, S.S., 2018. Biosignature preservations in gypsum veins and mineral crust of the atacama desert as an analog for Mars. 49th Lunar and Planetary Science Conference, abstract 2286.

Wierzchos, J., Davila, A.F., Artieda, O., Cámara-Gallego, B., de los Ríos, A., Nealson, K.H., Valea, S., Teresa García-González, M., Ascaso, C., 2013. Ignimbrite as a substrate for endolithic life in the hyper-arid Atacama Desert: implications for the search for life on Mars. Icarus, 224: 334-346.

Zent, A.P., Hecht, M.H., Hudson, T.L., Wood, S.E., Chevrier, V.F., 2016. A revised calibration function and results for the Phoenix mission TECP relative humidity sensor. Journal of Geophysical Research, 121: 626-651.

Zorzano, M.-P., Mateo-Martí, E., Prieto-Ballesteros, O., Osuna, S., Renno, N., 2009. Stability of liquid saline water on present day Mars. Geophysical Research Letters, 36: L20201. 